\title{
Measurement of low-ppm mixing ratios of water vapor in the upper troposphere and lower stratosphere using chemical ionization mass spectrometry
}

\author{
T. D. Thornberry ${ }^{1,2}$, A. W. Rollins ${ }^{1,2}$, R. S. Gao ${ }^{1}$, L. A. Watts ${ }^{1,2}$, S. J. Ciciora ${ }^{1}$, R. J. McLaughlin ${ }^{1}$, C. Voigt ${ }^{3,4}$, B. Hall ${ }^{5}$, \\ and D. W. Fahey ${ }^{1,2}$ \\ ${ }^{1}$ NOAA Earth System Research Laboratory, Chemical Sciences Division, Boulder, Colorado, USA \\ ${ }^{2}$ Cooperative Institute for Research in Environmental Sciences, University of Colorado, Boulder, Colorado, USA \\ ${ }^{3}$ Deutsches Zentrum für Luft- und Raumfahrt, Institut für Physik der Atmosphäre, Oberpfaffenhofen, Germany \\ ${ }^{4}$ Johannes Gutenberg-Universität, Institut für Physik der Atmosphäre, Mainz, Germany \\ ${ }^{5}$ NOAA Earth System Research Laboratory, Global Monitoring Division, Boulder, Colorado, USA \\ Correspondence to: T. D. Thornberry (troy.thornberry@ noaa.gov)
}

Received: 10 December 2012 - Published in Atmos. Meas. Tech. Discuss.: 14 January 2013

Revised: 9 April 2013 - Accepted: 29 April 2013 - Published: 4 June 2013

\begin{abstract}
A chemical ionization mass spectrometer (CIMS) instrument has been developed for the fast, precise, and accurate measurement of water vapor $\left(\mathrm{H}_{2} \mathrm{O}\right)$ at low mixing ratios in the upper troposphere and lower stratosphere (UT/LS). A low-pressure flow of sample air passes through an ionization volume containing an $\alpha$-particle radiation source, resulting in a cascade of ion-molecule reactions that produce hydronium ions $\left(\mathrm{H}_{3} \mathrm{O}^{+}\right)$from ambient $\mathrm{H}_{2} \mathrm{O}$. The production of $\mathrm{H}_{3} \mathrm{O}^{+}$ions from ambient $\mathrm{H}_{2} \mathrm{O}$ depends on pressure and flow through the ion source, which were tightly controlled in order to maintain the measurement sensitivity independent of changes in the airborne sampling environment. The instrument was calibrated every $45 \mathrm{~min}$ in flight by introducing a series of $\mathrm{H}_{2} \mathrm{O}$ mixing ratios between 0.5 and 153 parts per million (ppm, $10^{-6} \mathrm{~mol} \mathrm{~mol}^{-1}$ ) generated by Pt-catalyzed oxidation of $\mathrm{H}_{2}$ standards while overflowing the inlet with dry synthetic air. The CIMS $\mathrm{H}_{2} \mathrm{O}$ instrument was deployed in an unpressurized payload area aboard the NASA WB57F high-altitude research aircraft during the Mid-latitude Airborne Cirrus Properties Experiment (MACPEX) mission in March and April 2011. The instrument performed successfully during seven flights, measuring $\mathrm{H}_{2} \mathrm{O}$ mixing ratios below $5 \mathrm{ppm}$ in the lower stratosphere at altitudes up to $17.7 \mathrm{~km}$, and as low as $3.5 \mathrm{ppm}$ near the tropopause. Data were acquired at $10 \mathrm{~Hz}$ and reported as $1 \mathrm{~s}$ averages. In-flight calibrations demonstrated a typical sensitivity of
\end{abstract}

$2000 \mathrm{~Hz} \mathrm{ppm}^{-1}$ at $3 \mathrm{ppm}$ with a signal to noise ratio $(2 \sigma, 1 \mathrm{~s})$ greater than 32 . The total measurement uncertainty was 9 to $11 \%$, derived from the uncertainty in the in situ calibrations.

\section{Introduction}

Water vapor in the lower stratosphere (LS) plays significant roles in both stratospheric photochemistry and Earth's radiation budget (Forster and Shine, 2002; Brasseur and Solomon, 2005; Trenberth et al., 2007; Solomon et al., 2010) despite dehydration processes in the upper troposphere (UT) that reduce $\mathrm{H}_{2} \mathrm{O}$ mixing ratios to low part per million (ppm, $10^{-6} \mathrm{~mol} \mathrm{~mol}^{-1}$ ) levels. Over the past several decades there has been considerable systematic disagreement among in situ $\mathrm{H}_{2} \mathrm{O}$ measurements made by different instruments at the low mixing ratios found in the UT/LS. These discrepancies have limited our understanding of the microphysics related to cirrus cloud particle nucleation and growth which underlies the dehydration processes in the tropical UT that regulate $\mathrm{H}_{2} \mathrm{O}$ transport across the tropopause (Jensen et al., 2005, 2008; Peter et al., 2006; Krämer et al., 2009) and which, in turn, limits our ability to determine and predict the effect of climate changes on the radiatively important feedback from UT/LS $\mathrm{H}_{2} \mathrm{O}$ (Solomon et al., 2010; Maycock et al., 2011). 
$\mathrm{H}_{2} \mathrm{O}$ in the UT/LS is measured from aircraft and balloons using a variety of in situ techniques including Lyman$\alpha$ photofragment fluorescence (e.g., Weinstock et al., 1994; Zöger et al., 1999), tunable diode laser absorption spectroscopy (e.g., May, 1998), and chilled mirror hygrometry (e.g., Vömel et al., 2007). UT/LS $\mathrm{H}_{2} \mathrm{O}$ is also measured remotely using Raman lidar from the ground (Leblanc et al., 2012) and differential absorption lidar (DIAL) from aircraft (Kiemle et al., 2008), and by satellite instruments such as the Michelson Interferometer for Passive Atmospheric Sounding (MIPAS) on EnviSat (Milz et al., 2005) and the Microwave Limb Sounder (MLS) on Aura (Read et al., 2001). One commonality among all current UT/LS $\mathrm{H}_{2} \mathrm{O}$ instruments is a lack of in situ calibration. Instruments are typically calibrated on the ground before and after missions, between individual flights, or by comparison to a reference method (e.g., direct absorption) at lower altitudes with higher mixing ratios, and rely on assumed consistency of instrumental background and sensitivity to apply the calibrations to flight conditions in the UT/LS.

Significant effort has been expended to assess the accuracy of UT/LS $\mathrm{H}_{2} \mathrm{O}$ measurements (Weinstock et al., 1994, 2009; Hintsa et al., 1999; Kley et al., 2000; Fahey et al., 2009). Both in-flight and laboratory comparisons have demonstrated persistent differences among instruments at mixing ratios below $10 \mathrm{ppm}$, with significantly larger differences observed in the UT/LS than in the laboratory. The in-flight differences have typically been much greater than the combined instrumental uncertainties, and indicate the presence of unrecognized artifacts in some or all of the instruments.

To address these issues related to the accuracy of UT/LS $\mathrm{H}_{2} \mathrm{O}$ measurements, we have developed a sensitive and specific chemical ionization mass spectrometry (CIMS) technique for the measurement of $\mathrm{H}_{2} \mathrm{O}$ at low-ppm mixing ratios. We have adapted an existing CIMS instrument capable of operating on high-altitude research aircraft to make measurements of UT/LS $\mathrm{H}_{2} \mathrm{O}$. The instrument conducts in situ calibration procedures during flight using two separate sources to ensure the accuracy of in-flight measurements. The instrument has been successfully operated in the UT/LS aboard the NASA WB-57F high-altitude research aircraft.

\section{Instrument description}

\subsection{General description}

A schematic of the CIMS $\mathrm{H}_{2} \mathrm{O}$ instrument, including the principal components of the sampling and calibration flow systems, is shown in Fig. 1. The instrument is a modification of the CIMS instrument described by Neuman et al. (2000) previously used to measure nitric acid $\left(\mathrm{HNO}_{3}\right)$ and hydrochloric acid $(\mathrm{HCl})$ in the UT/LS. Minor changes were made to the quadrupole mass spectrometer electronics to convert the instrument from measuring negative ions to positive ions; the control software was rewritten for improved operation and to allow greater flexibility in the autonomous operation sequence; the long ionization flow tube was replaced with a compact, custom ion source; and one of the four turbomolecular pumps was removed and replaced with a second molecular drag pump to provide low pressure pumping for the ion source. Only one channel of the twochannel instrument was converted for $\mathrm{H}_{2} \mathrm{O}$ measurements, and the other channel was not operated. The NOAA CIMS instrument was designed to function in the unpressurized and unheated fuselage payload bay of the NASA WB-57F aircraft, with sensitive components such as the quadrupole power supply and data acquisition computer system located in temperature and pressure controlled enclosures. A design principle of the instrument is to utilize highly regulated internal temperatures, pressures, and flows in order to produce an analytical measurement that is independent of changes in the sampling environment during flight. The instrument operates and is calibrated identically in flight and in the laboratory.

\subsection{Inlet system}

The CIMS $\mathrm{H}_{2} \mathrm{O}$ sampling point was located at the bottom of a pylon extending $40 \mathrm{~cm}$ below the aircraft fuselage pallet. The pylon is indicated in the schematic in Fig. 1, and a drawing of the pylon showing the inlet flow control valve, zero air and calibration valves, and the ion source appears in Fig. 2. This location places the sampling point outside the aircraft boundary layer, which avoids possible contamination (i.e., artifact) from outgassing of $\mathrm{H}_{2} \mathrm{O}$ from aircraft surfaces. Sample air is drawn through a $0.32 \mathrm{~cm}$ orifice at the tip of the inlet line, which consists of $0.46 \mathrm{~cm}$ ID (inner diameter) electropolished stainless steel tubing (WinTech 10, Winter Technologies). The ambient air flow past the sampling point is set by a flow straightener and, hence, is perpendicular to the flow into the inlet line allowing for sampling of $\mathrm{H}_{2} \mathrm{O}$ vapor while rejecting cloud droplets and ice crystals (Popp et al., 2004). The tip of the inlet is heated to $\sim 45^{\circ} \mathrm{C}$ in order to prevent condensation on the inlet.

The first $5 \mathrm{~cm}$ length of the inlet line is enclosed in a heating mantle which heats the ambient sample flow to $45^{\circ} \mathrm{C}$, and the air within the pylon was maintained near $30^{\circ} \mathrm{C}$ in flight in order to keep all non-heated components near normal room temperatures. During calibration, dry synthetic air (zero air) is added to the inlet $3 \mathrm{~cm}$ from the sampling point through a $0.2 \mathrm{~cm}$ ID stainless steel tube brazed into the inlet tube. Calibration gas is added through a second $0.2 \mathrm{~cm}$ ID tube brazed into the inlet tube $15 \mathrm{~cm}$ downstream of the inlet tip. This arrangement allows for standard addition of $\mathrm{H}_{2} \mathrm{O}$ to the ambient air sample as well as zero air, and the addition of the calibration gas well downstream of the zero air ensures that all of the calibration gas sent to the inlet flows into the instrument. 


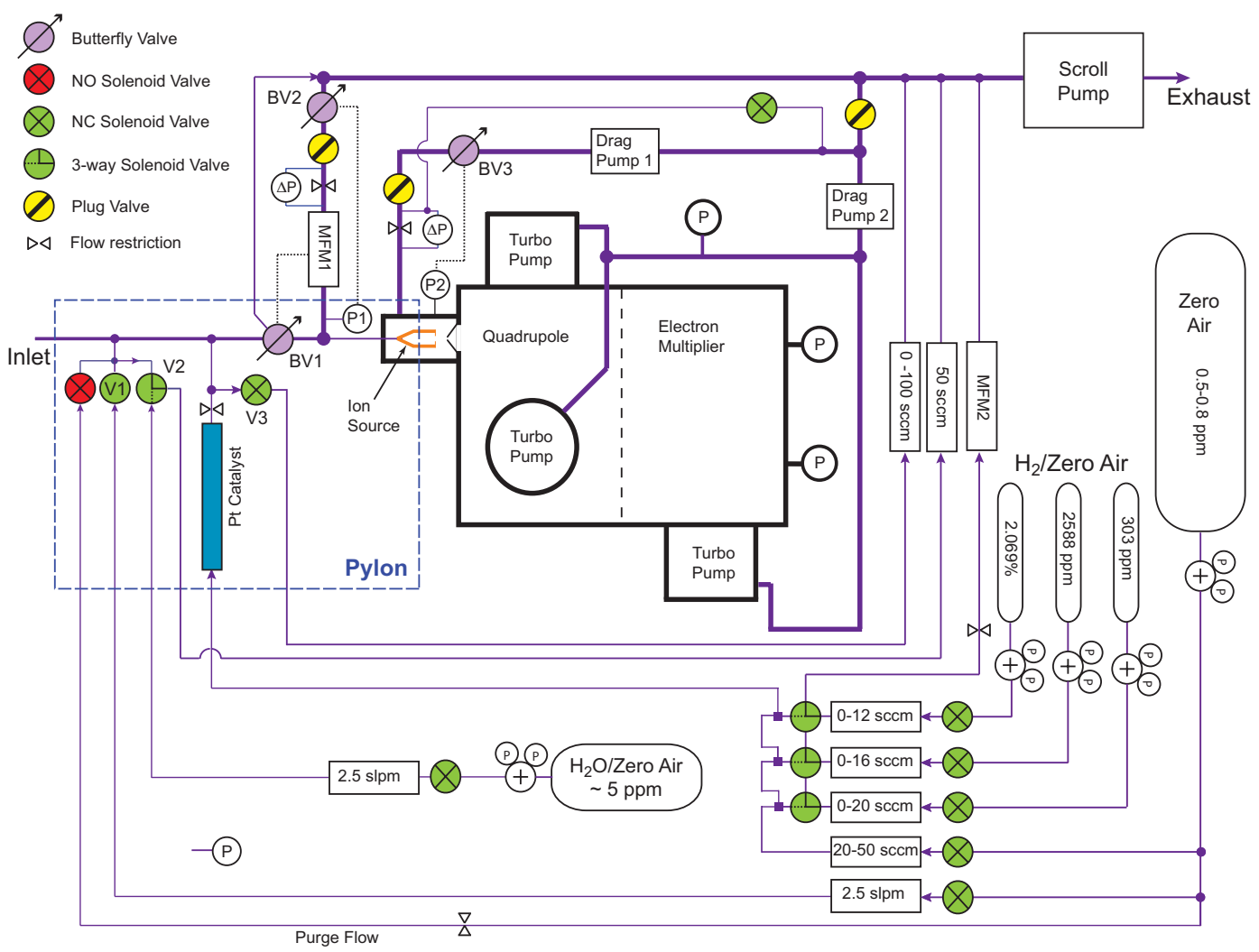

Fig. 1. Schematic of the CIMS instrument showing the principal components of the flow and calibration systems. A custom butterfly valve (BV1) controls the inlet sample mass flow measured by mass flow meter MFM1. BV2 regulates the main inlet pressure (P1), and BV3 regulates the ion source pressure (P2). Solenoid valve V1 is the zero air delivery valve, $\mathrm{V} 2$ is the $\mathrm{H}_{2} \mathrm{O}$ standard delivery valve, and $\mathrm{V} 3$ is the $\mathrm{H}_{2} / \mathrm{Pt}-\mathrm{H}_{2} \mathrm{O}$ calibration diversion valve. Mass flow controller flows or flow ranges during operation are specified. NO and NC denote normally open and normally closed solenoid valves.

\subsubsection{Flow and pressure control}

An essential feature of the inlet sample flow control is to maintain the pressure and flow conditions in the ion source constant over a wide range of ambient pressures. To achieve this control, three custom butterfly valves are used to hold the pressures constant at the ion source inlet and within the ion source chamber. The valves are of a design similar to that described in Gao et al. (1999) that were developed for the $\mathrm{HNO}_{3}$ CIMS instrument (Neuman et al., 2000). The new valves are constructed of stainless steel instead of the original Teflon ${ }^{\circledR}$ to minimize $\mathrm{H}_{2} \mathrm{O}$ interactions with the valve surfaces. The first butterfly valve (BV1, Fig. 1) controls the inlet flow to 1460 standard $\mathrm{cm}^{3}$ per minute $(\mathrm{sccm})$ using the signal from a mass flow meter (Model AWM5101, Honeywell) located in the main inlet flow downstream of the pylon structure (MFM1, Fig. 1). The second butterfly valve (BV2), located downstream of the pylon and the ion source inlet, is servo controlled to maintain constant pressure in the inlet using the signal from the main flow pressure transducer $(\mathrm{P} 1)$. The ion source pressure is controlled by the third butterfly valve (BV3) that is servo controlled by the ion source chamber pressure and pumped directly by a molecular drag pump (Drag Pump 2). The pressure in the main inlet was controlled to $18.5 \pm 0.04 \mathrm{hPa}$ while that in the ion source was maintained at $1.6 \pm 0.01 \mathrm{hPa}$. This pressure difference produced a constant flow near $60 \mathrm{sccm}$ through an $18 \mathrm{~cm}$ long, $0.18 \mathrm{~cm}$ ID electropolished stainless steel capillary into the ion source. The pressures inside the inlet system and ion source were held constant to within their respective tolerances during flights, while the aircraft operated over a wide range of ambient pressures $(600-80 \mathrm{hPa})$ and temperatures (280-195 K).

Minimizing the residence time of the ambient sample in the instrument inlet before it reaches the ion source chamber also minimizes the response time of the instrument to rapid variations in ambient $\mathrm{H}_{2} \mathrm{O}$. The $28.5 \mathrm{~cm}$ long, nearambient pressure region of the inlet from the sampling point to the flow control valve (BV1) had a volume of $4.7 \mathrm{~cm}^{3}$ and presented the dominant source of sample residence time. At the inlet sample flow rate (main flow + ion source flow) of $1520 \mathrm{sccm}$, the resulting sample residence time was $<0.1 \mathrm{~s}$ at ambient pressures below $500 \mathrm{hPa}$. 


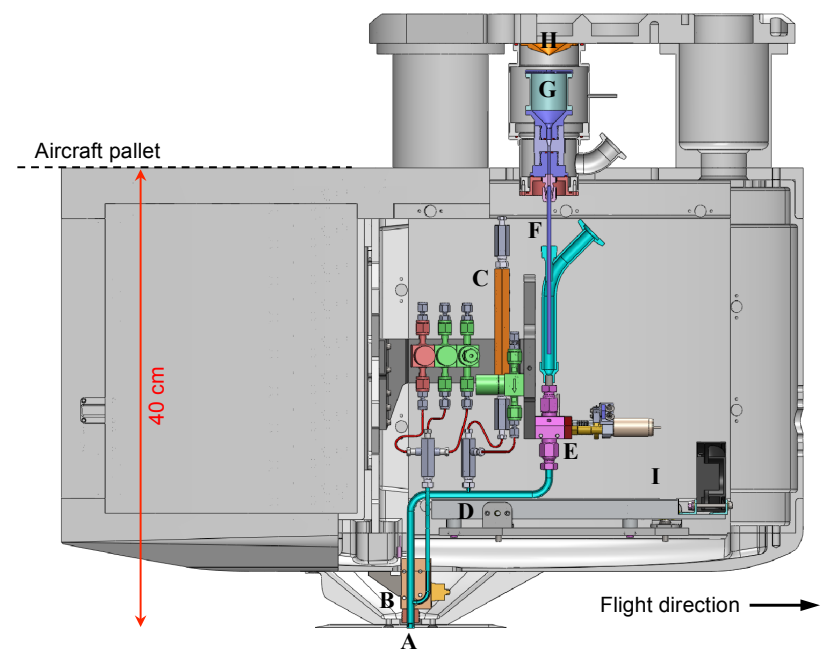

Fig. 2. Model of the CIMS $\mathrm{H}_{2} \mathrm{O}$ inlet pylon showing the inlet geometry and components of the flow and calibration system. Ambient air enters the instrument through the sample point (A) in the center of the thin flow straightener plate at the bottom of the pylon. The zero air addition point (B) is located $3 \mathrm{~cm}$ downstream of the sample point. The principal calibration source is $\mathrm{H}_{2} \mathrm{O}$ produced by $\mathrm{H}_{2}$ oxidation in a Pt catalyst (C), which is added to the inlet flow (D) $15 \mathrm{~cm}$ from the sample point. A custom butterfly valve (E) maintains a constant mass flow through the inlet independent of the ambient pressure. A small fraction of the sample flow is extracted through a stainless steel capillary (F) and flows into the ion source (G). Ions produced in the ion source enter the mass spectrometer (not shown) through the entrance nose cone $(\mathrm{H})$. A fan and heater (I) are used to heat the interior of the pylon to near $30^{\circ} \mathrm{C}$ during flight.

\subsubsection{Materials}

Prior to the development of the flight instrument inlet, laboratory studies were performed using a prototype of the CIMS $\mathrm{H}_{2} \mathrm{O}$ instrument to characterize different inlet line materials for their $\mathrm{H}_{2} \mathrm{O}$ desorption properties. A fast solenoid valve controlling $\mathrm{H}_{2} \mathrm{O}$ addition to the CIMS $\mathrm{H}_{2} \mathrm{O}$ sampling line was used to create a sharp transition from $\sim 50 \mathrm{ppm}$ to less than $1 \mathrm{ppm}$. The resulting decays were reasonably well represented by a triple exponential function with overall time constants ( $3 e$-folding) of $<5 \mathrm{~s}$. Only small differences were observed in the desorption time constants for $500 \mathrm{sccm}$ flows through $50 \mathrm{~cm}$ lengths of $0.64 \mathrm{~cm}$ OD (outer diameter) electropolished stainless steel, fluoropolymer-coated (Fluoropel 504A-FS, Cytonix Corp.) stainless steel, borosilicate glass, PFA Teflon ${ }^{\circledR}$, and Synflex 1300 (Eaton Corp.) tubing. The Teflon ${ }^{\circledR}$ tubing was observed to allow measurable $\mathrm{H}_{2} \mathrm{O}$ permeation and is therefore not a suitable material for use in instruments measuring low ppm mixing ratios of $\mathrm{H}_{2} \mathrm{O}$. With the additional considerations of ease and flexibility of manufacturing and minimization of trapped volume, the wetted components of the flight instrument inlet were all constructed of electropolished stainless steel.

\subsection{Ion source}

In contrast to typical chemical ionization techniques for the measurement of atmospheric trace species (e.g., Huey, 2007), no separate reagent ion flow was used for detection of $\mathrm{H}_{2} \mathrm{O}$ in the new CIMS technique. Instead, a flow of sample air was directed through the ion source chamber and exposed directly to $\alpha$ particles emitted from the radioactive source. The resulting cascade of ion-molecule reactions produced protonated water ions $\left(\mathrm{H}_{3} \mathrm{O}^{+}\right)$as a stable end product, with the number of $\mathrm{H}_{3} \mathrm{O}^{+}$ions monotonically related to the $\mathrm{H}_{2} \mathrm{O}$ mixing ratio. Optimization of the ion source pressure to achieve a balance between dynamic range and sensitivity $\left(\mathrm{Hz} \mathrm{ppm}^{-1}\right)$ to $\mathrm{H}_{2} \mathrm{O}$ required operation at low pressure. The source pressure of less than a few $\mathrm{hPa}$, required to prevent saturation of the $\mathrm{H}_{3} \mathrm{O}^{+}$signal at a low $\mathrm{H}_{2} \mathrm{O}$ mixing ratio, is lower than is typically used in CIMS instruments for atmospheric measurements (Huey, 2007). Standard ${ }^{210}$ Po ionization sources (e.g. Staticmaster P-2031, NRD, LLC) that are often used in CIMS instruments are designed to work at much higher pressures and flow rates than are optimal for the new CIMS application. At low pressures, fewer ions are produced per $\alpha$ particle emitted into the source volume, and at low flow rates, the loss of ions to surfaces and recombination before they can exit the source is significantly increased. To address these issues, a custom ion source was designed and constructed to improve performance at the low pressure, low flow conditions optimal for the CIMS $\mathrm{H}_{2} \mathrm{O}$ measurement.

The custom ion source chamber, shown in Fig. 3, is a cylinder $3.2 \mathrm{~cm}$ long and $3.1 \mathrm{~cm}$ ID with a $3.2 \mathrm{~cm} \times 9.6 \mathrm{~cm}$ ${ }^{241} \mathrm{Am}$ foil (NRD, LLC) mounted on the inner surface. The total activity of the ${ }^{241} \mathrm{Am}$ foil is $7.2 \mathrm{mCi}$, of which approximately $15 \%$ is emitted into the ion source volume (NRD, LLC, personal communication, 2010). The end cap of the ion source is comprised of two metal discs with circular openings, separated by a thin insulating disk of plastic $\left(\mathrm{Kel}-\mathrm{F}^{\circledR}\right)$. The inner disc is at the same potential as the body of the ion source, while the outer disc is biased at a lower potential to provide an attractive potential for the efficient extraction of positive ions from the ion source chamber. The ion source body and end caps were machined from a heavy tungsten alloy to provide adequate shielding from the gamma rays coemitted from the ${ }^{241} \mathrm{Am}$ foil and then gold plated for inertness prior to installation of the foil.

In order to improve ion extraction from the ion source chamber, transmission of ions into the mass spectrometer, and ion declustering, the ion source body and extraction lens were maintained at positive potentials relative to the mass spectrometer entrance nose cone, which was held at ground potential. The ion source body was held at $+140 \mathrm{~V}$ relative to the nose cone and the extraction lens was held at $+90 \mathrm{~V}$. These voltages produced a $-50 \mathrm{~V}$ attractive potential to extract positive ions from the ion source and a $\sim 70 \mathrm{~V} \mathrm{~cm}^{-1}$ field to accelerate the ions to the entrance to the mass spectrometer. 


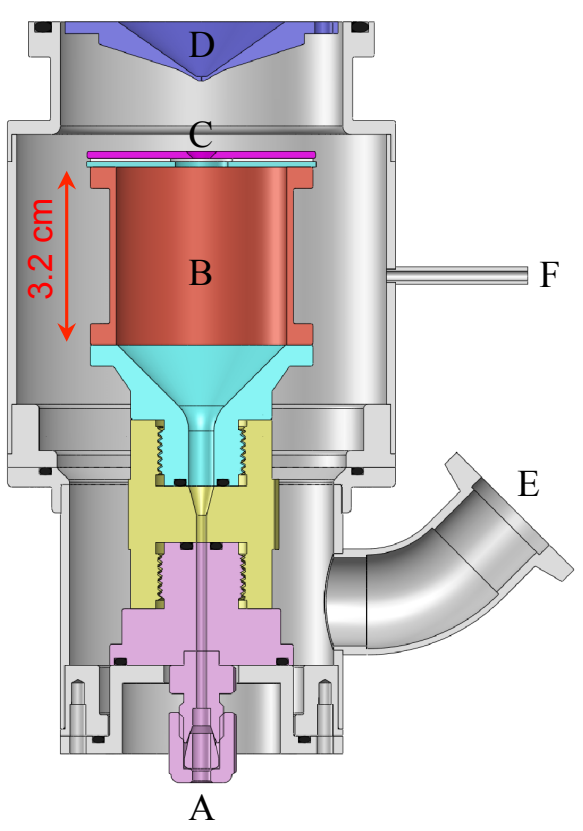

Fig. 3. Custom ion source for the CIMS $\mathrm{H}_{2} \mathrm{O}$ measurement. Air enters the ion source chamber through a capillary connected to the fitting (A) at the bottom. The ${ }^{241} \mathrm{Am}$ foil is located on the inside of the ion source chamber (B), which is held at a $+140 \mathrm{~V}$ potential with respect to ground. Positive ions formed inside the chamber are extracted through the exit lens $(\mathrm{C})$ by applying a $+90 \mathrm{~V}$ potential to the lens $(-50 \mathrm{~V}$ relative to the chamber). The ions exit the chamber directly in front of the entrance nose cone of the mass spectrometer (D), which is held near ground potential. Air flowing through the ion source chamber is pumped away through port $(\mathrm{E})$ on the vacuum can, while the pressure is monitored through a smaller port $(\mathrm{F})$.

The custom ${ }^{241} \mathrm{Am}$ ion source yielded a factor of 2 increase in total ion current over a $20 \mathrm{mCi}$ commercial ${ }^{210} \mathrm{Po}$ source (model P-2031, NRD, LLC) when operating at pressures below $2 \mathrm{hPa}$ and a flow of $1000 \mathrm{sccm}$. This improved signal was maintained while operating with flows as low as $30 \mathrm{sccm}$, at which almost no $\mathrm{H}_{3} \mathrm{O}^{+}$signal was observed using the commercial ${ }^{210} \mathrm{Po}$ source. The ${ }^{241} \mathrm{Am}$ foil, with a half-life of $432.2 \mathrm{yr}$, has an advantage over ${ }^{210} \mathrm{Po}$ (half-life 138 days) in that its activity will remain stable essentially indefinitely, barring damage to the foil, thus eliminating the need to periodically replace the radioactive source as its activity declines.

\subsubsection{Ionization mechanism}

The $\alpha$ particles emitted by the ${ }^{241} \mathrm{Am}$ foil are energetic enough to ionize any molecule they encounter on their passage across the ion source chamber, so the bulk of the ions are initially formed from interaction with $\mathrm{N}_{2}$ and $\mathrm{O}_{2}$ (Takebe, 1974):

$$
\begin{aligned}
& \mathrm{N}_{2} \stackrel{\alpha}{\longrightarrow} \mathrm{N}_{2}^{+}+e^{-} \\
& \stackrel{\alpha}{\longrightarrow} \mathrm{N}^{+}+\mathrm{N}+e^{-} \\
& \mathrm{O}_{2} \stackrel{\alpha}{\longrightarrow} \mathrm{O}_{2}^{+}+e^{-} \\
& \stackrel{\alpha}{\longrightarrow} \mathrm{O}^{+}+\mathrm{O}+e^{-}
\end{aligned}
$$

The $\mathrm{N}_{2}^{+}, \mathrm{N}^{+}$and $\mathrm{O}^{+}$ions are rapidly converted to $\mathrm{O}_{2}^{+}$with minor branches producing stable $\mathrm{NO}^{+}$ions. A small fraction of the $\mathrm{N}_{2}^{+}$ions react with $\mathrm{H}_{2} \mathrm{O}$ to produce $\mathrm{N}_{2} \mathrm{H}^{+}$ions, which can subsequently react with an additional $\mathrm{H}_{2} \mathrm{O}$ molecule to produce $\mathrm{H}_{3} \mathrm{O}^{+}$. Kinetic modeling indicates that the dominant channel for producing $\mathrm{H}_{3} \mathrm{O}^{+}$is through a series of reactions beginning with the association of $\mathrm{O}_{2}^{+}$with $\mathrm{H}_{2} \mathrm{O}$ (Reaction R3) or with another $\mathrm{O}_{2}$ molecule to form $\mathrm{O}_{4}^{+}$(Reaction $\mathrm{R} 4$ ), which can then form $\mathrm{H}_{3} \mathrm{O}^{+}$clusters in a series of reactions involving multiple $\mathrm{H}_{2} \mathrm{O}$ molecules (Fehsenfeld et al., 1971; Anicich, 2003):

$$
\begin{aligned}
& \mathrm{O}_{2}^{+}+\mathrm{H}_{2} \mathrm{O}+\mathrm{M} \rightarrow \mathrm{O}_{2}^{+} \cdot \mathrm{H}_{2} \mathrm{O}+\mathrm{M} \\
& \mathrm{O}_{2}^{+}+\mathrm{O}_{2}+\mathrm{M} \rightarrow \mathrm{O}_{4}^{+}+\mathrm{M} \\
& \mathrm{O}_{4}^{+}+\mathrm{H}_{2} \mathrm{O}+\mathrm{M} \rightarrow \mathrm{O}_{2}^{+} \cdot \mathrm{H}_{2} \mathrm{O}+\mathrm{O}_{2}+\mathrm{M} \\
& \mathrm{O}_{2}^{+} \cdot \mathrm{H}_{2} \mathrm{O}+\mathrm{H}_{2} \mathrm{O} \rightarrow \mathrm{H}_{3} \mathrm{O}^{+} \cdot \mathrm{OH}+\mathrm{O}_{2} \\
& \mathrm{H}_{3} \mathrm{O}^{+} \cdot \mathrm{OH}+\mathrm{H}_{2} \mathrm{O} \rightarrow \mathrm{H}_{3} \mathrm{O}^{+} \cdot \mathrm{H}_{2} \mathrm{O}+\mathrm{OH}
\end{aligned}
$$

The ionization mechanism is shown schematically in Fig. 4. This ion chemistry is similar to that occurring in the D region of the ionosphere (Ferguson, 1974). The multistep and multi- $\mathrm{H}_{2} \mathrm{O}$ nature of the reaction mechanism results in a nonlinear relationship between the $\mathrm{H}_{2} \mathrm{O}$ mixing ratio and number of $\mathrm{H}_{3} \mathrm{O}^{+}$ions produced. The important role of three-body reactions (R3), (R4) and (R5) in the ionization mechanism leads to a large pressure dependence of the $\mathrm{H}_{3} \mathrm{O}^{+}$product ion yield. Maintaining a constant ion source pressure is thus critical in order to produce a consistent measurement sensitivity.

The ion-molecule clusters are all dissociated by energetic ion-molecule collisions induced by the strong electric field used to accelerate the ions from the ion source into the mass spectrometer, thereby converting all of the $\mathrm{H}_{3} \mathrm{O}^{+} \cdot \mathrm{OH}$ and $\mathrm{H}_{3} \mathrm{O}^{+} \cdot\left(\mathrm{H}_{2} \mathrm{O}\right)_{n}$ into $\mathrm{H}_{3} \mathrm{O}^{+}$. The observed mass spectra for two example mixing ratios of $\mathrm{H}_{2} \mathrm{O}$ are shown in Fig. 5. The well-defined $\mathrm{H}_{3} \mathrm{O}^{+}$signal at mass-to-charge ratio $(\mathrm{m} / \mathrm{z}) 19$ is used to quantify the $\mathrm{H}_{2} \mathrm{O}$ in the sample flow. The largely $\mathrm{H}_{2} \mathrm{O}$-independent $\mathrm{NO}^{+}$signal at $m / z 30$ serves as a useful diagnostic for tracking the stability of the ion source and mass spectrometer, and the $\mathrm{O}_{2}^{+}$signal at $m / z 32$ represents the majority of the ion current at low $\mathrm{H}_{2} \mathrm{O}$ mixing ratios. An initial plan was to normalize the $\mathrm{H}_{3} \mathrm{O}^{+}$signal by the $\mathrm{NO}^{+}$signal to account for any changes in ion transmission through the ion optics and quadrupole mass filter. However, 


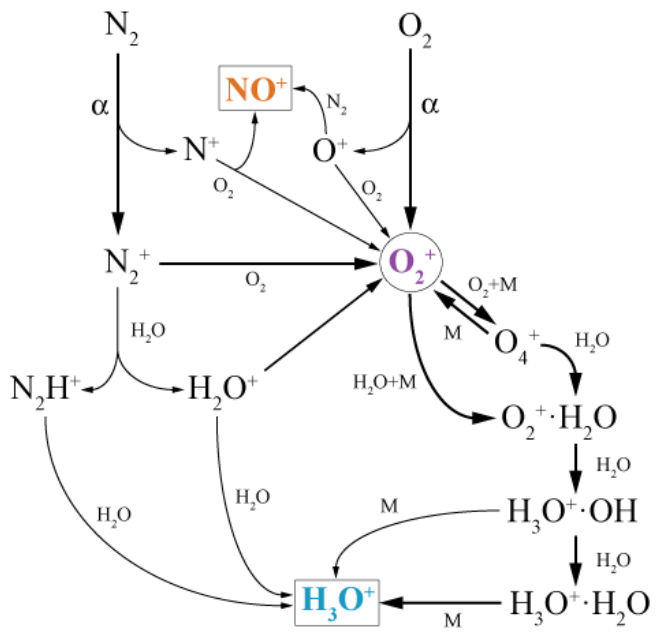

Fig. 4. Schematic showing the principal ionization pathways for the production of $\mathrm{H}_{3} \mathrm{O}^{+}$from $\alpha$-particle ionization of ambient air. $x+\mathrm{M}$ indicates a three-body reaction, $\mathrm{M}$ indicates a declustering collision. The arrows indicate the flow of charge through the reaction mechanism.

optimal operation of the quadrupole required different parameter settings in the $m / z 16-22$ window and the $m / z 27-$ 44 window, which resulted in differences in the variations in peak position and transmission between the two windows. This rendered such a normalization non-useful. The effective declustering of ions prior to entering the mass spectrometer is demonstrated by the complete absence of any signal from $\mathrm{H}_{3} \mathrm{O}^{+} \cdot \mathrm{H}_{2} \mathrm{O}$ at $m / z 37$.

\subsubsection{Interferences}

Due to the relatively high abundance of $\mathrm{H}_{2} \mathrm{O}$ compared to most other atmospheric trace gases in the UT/LS (especially those containing hydrogen atoms), significant chemical interferences are not expected in the ionization scheme producing $\mathrm{H}_{3} \mathrm{O}^{+}$as outlined above. To quantify the potential effects on the $\mathrm{H}_{3} \mathrm{O}^{+}$signal from the most abundant atmospheric trace species, laboratory experiments were conducted by adding $\mathrm{O}_{3}, \mathrm{CO}_{2}$ and $\mathrm{CH}_{4}$ along with $\mathrm{H}_{2} \mathrm{O}$ to dry $\left(\sim 0.5 \mathrm{ppm} \mathrm{H}_{2} \mathrm{O}\right)$ synthetic zero air (Ultra Zero Air, Scott-Marrin, Inc.). These mixtures were introduced into the $\mathrm{CIMS}_{2} \mathrm{O}$ instrument and the $\mathrm{H}_{3} \mathrm{O}^{+}$signal response to $\mathrm{H}_{2} \mathrm{O}$ mixing ratio was observed as the mixing ratios of the other species were varied. $\mathrm{O}_{3}$ at mixing ratios up to several ppm was found to have no effect on the measured $\mathrm{H}_{2} \mathrm{O}$ sensitivity. $\mathrm{CH}_{4}$ in the sample flow produced an $\mathrm{H}_{3} \mathrm{O}^{+}$signal with approximately $1 \%$ of the sensitivity to $\mathrm{H}_{2} \mathrm{O}$. Adding $380 \mathrm{ppm} \mathrm{CO}_{2}$ to the zero air resulted in a decrease in sensitivity to $\mathrm{H}_{2} \mathrm{O}$ of $\sim 10 \%$.

Zero air containing mixing ratios of $\mathrm{CO}_{2}$ and $\mathrm{CH}_{4}$ similar to current ambient values, $380 \mathrm{ppm}$ and $1.8 \mathrm{ppm}$, respectively, was found to yield a sensitivity to $\mathrm{H}_{2} \mathrm{O}$ indistinguishable from that obtained using a desiccated ambient

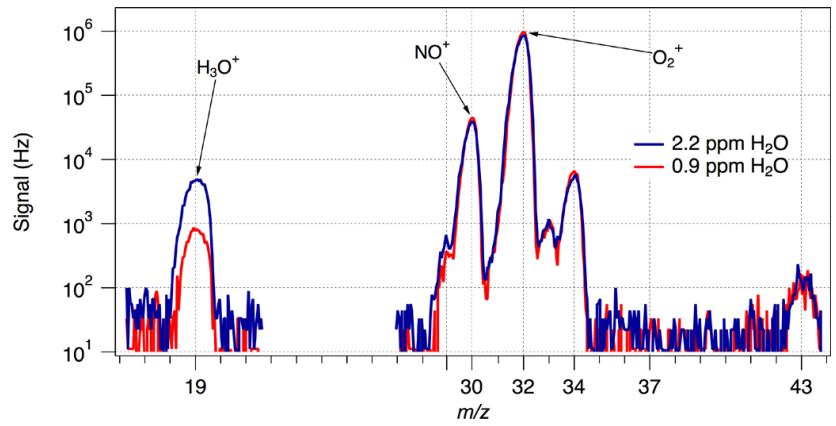

Fig. 5. Observed mass spectra with 0.9 (red) and 2.2 (blue) ppm $\mathrm{H}_{2} \mathrm{O}$ in the sample flow. The complete declustering of ions entering the mass spectrometer is demonstrated by the absence of a peak corresponding to $\mathrm{H}_{3} \mathrm{O}^{+} \cdot \mathrm{H}_{2} \mathrm{O}$ at $m / z 37$.

air standard prepared by the NOAA Earth System Research Lab Global Monitoring Division. To account for the minor $\mathrm{CO}_{2}$ and $\mathrm{CH}_{4}$ effects, the synthetic zero air used in the laboratory and in flight contained $380( \pm 8) \mathrm{ppm} \mathrm{CO}_{2}$ and $1.78( \pm 0.04) \mathrm{ppm} \mathrm{CH}_{4}$ (Scott-Marrin, Inc.) to simulate ambient air concentrations.

\subsection{Calibration system}

Calibration of the CIMS $\mathrm{H}_{2} \mathrm{O}$ instrument in flight and in the laboratory was accomplished using two independent $\mathrm{H}_{2} \mathrm{O}$ sources. The primary calibration source was quantitative oxidation of $\mathrm{H}_{2}$ in zero air over a Pt catalyst to produce known mixing ratios of $\mathrm{H}_{2} \mathrm{O}$. The development and evaluation of this calibration source is described in detail by Rollins et al. (2011). For calibration of the CIMS instrument, a series of stepped flows $(\leq 20 \mathrm{sccm}$ each) from three different standards of $\mathrm{H}_{2}$ in air $(303 \pm 6 \mathrm{ppm}, 2588 \pm 24 \mathrm{ppm}$, and $2.069 \pm 0.021 \%$, Scott-Marrin, Inc.) were combined with a $50 \mathrm{sccm}$ flow of zero air and passed through a Pt catalyst. The catalyst was located in the inlet pylon so that the $\mathrm{H}_{2}$ was converted to $\mathrm{H}_{2} \mathrm{O}$ immediately prior to the calibration flow being added to the sample flow. The catalyst consisted of a $14 \mathrm{~cm}$ long, $0.22 \mathrm{~cm}$ ID Pt tube with two $2.5 \mathrm{~cm} \times 5 \mathrm{~cm}$ pieces of 100 mesh Pt gauze (Sigma-Aldrich) rolled up and packed loosely inside. A $10 \mathrm{~cm}$ long copper block containing a cartridge heater was clamped around the Pt tube and the assembly insulated with rigid silica foam. The catalyst was maintained at a constant temperature of $180^{\circ} \mathrm{C}$, which results in quantitative oxidation ( $>99 \%$ ) of the $\mathrm{H}_{2}$ in the flow to $\mathrm{H}_{2} \mathrm{O}$ (Rollins et al., 2011). A $100 \mu \mathrm{m}$ orifice at the exit of the catalyst tube maintained the pressure in the catalyst at greater than $1000 \mathrm{hPa}$, independent of the lower sample line pressure. In the primary procedure for instrument calibration in flight and in the laboratory, the calibration flow from the catalyst containing $\mathrm{H}_{2} \mathrm{O}$ was added to a sample flow of zero air with known residual $\mathrm{H}_{2} \mathrm{O}$, thereby producing accurately known $\mathrm{H}_{2} \mathrm{O}$ mixing ratios in the instrument. 
The secondary calibration source was a gravimetricallyprepared $\mathrm{H}_{2} \mathrm{O}$-in-zero-air standard. The cylinder zero air balance gas contained $\mathrm{CO}_{2}$ and $\mathrm{CH}_{4}$ as described above for the sample flow zero air. The $\mathrm{H}_{2} \mathrm{O}$ standard was stored in a $34 \mathrm{~L}$ electropolished stainless steel cylinder (Essex Industries) in which low $\mathrm{H}_{2} \mathrm{O}$ mixing ratios have been shown in NOAA tests to be stable to within a few percent for periods of up to several years. A subsample from this cylinder was transferred to a $4.5 \mathrm{~L}$ electropolished stainless steel cylinder (Essex Industries) in the instrument for use during flight. A $2500 \mathrm{sccm}$ flow from this standard was delivered to the inlet line using valve V2 (Fig. 1) in place of zero air or ambient sample, thereby producing an independent, absolute, single calibration point that could be used to confirm the accuracy of the multipoint dynamic-dilution $\mathrm{H}_{2}$ catalyst calibration in flight.

In order to maintain flow through the calibration system while not adding calibration gas to the inlet, and to minimize dead volume and wetted surface area in the calibration line, the $\mathrm{H}_{2} / \mathrm{Pt} \mathrm{H}_{2} \mathrm{O}$ calibration flow is diverted from the inlet to the instrument vacuum pump by means of a tee and 2-way valve (V3) when it is not needed. The diverted calibration flow passes through a mass flow controller, which is set to also take a small amount $(<50 \mathrm{sccm})$ of air from the sample line to ensure complete diversion of the calibration flow. Switching this valve allows the calibration gas to be rapidly added or removed from the sample flow.

The calibration flows were controlled using Bronkhorst EL-Flow thermal mass flow controllers (Bronkhorst HighTech B.V., the Netherlands). Previous experience with thermal mass flow controllers aboard unpressurized high-altitude aircraft has indicated that errors in the reported flow could result from operation at low ambient pressure external to the flow controller. In laboratory tests, the Bronkhorst flow controllers used in the CIMS instrument were found to be insensitive $(<-1 \%$ deviation) to external ambient pressure at pressures down to $80 \mathrm{hPa}$, which was the lowest pressure reached in the WB-57F payload bay. At lower pressures, larger errors in the reported flow were observed, reaching $-10 \%$ at $22.5 \mathrm{hPa}$ and $-25 \%$ at the lowest pressure tested of $17 \mathrm{hPa}$.

\section{Instrument performance}

\subsection{Laboratory evaluation}

\subsubsection{Sensitivity}

The multiple reaction paths and multiple steps in the ionization mechanism (Fig. 4) leading to the production of $\mathrm{H}_{3} \mathrm{O}^{+}$result in a non-linear response to $\mathrm{H}_{2} \mathrm{O}$ in the CIMS instrument (Fig. 6). At low mixing ratios ( $<10 \mathrm{ppm}), \mathrm{H}_{2} \mathrm{O}$ is the limiting reagent in multiple steps in the ionization mechanism and, thus, the sensitivity is greater than first order in $\mathrm{H}_{2} \mathrm{O}$. At higher mixing ratios ( $>10 \mathrm{ppm}$ ), the availability of
$\mathrm{O}_{2}^{+}$becomes limiting and the sensitivity begins to decrease with increasing $\mathrm{H}_{2} \mathrm{O}$. The combination of these two effects leads to an overall sigmoidal shape to the instrument sensitivity function. The ionization mechanism also involves three-body reactions and, therefore, the sensitivity is a strong function of the ion source pressure. With the active control of the pressure in the ion source to within $\pm 0.01 \mathrm{hPa}$, no sensitivity changes due to pressure variations could be detected.

Due to the non-linearity of the instrument response, the calibration of instrument sensitivity to $\mathrm{H}_{2} \mathrm{O}$ requires the addition of multiple $\mathrm{H}_{2} \mathrm{O}$ mixing ratios spanning the measurement range of interest in the ambient atmosphere. Further, a means of interpolating between the individual calibration points is necessary to provide a smooth function of the sensitivity over the mixing ratio range. Several different interpolation approaches were considered, including linear and spline interpolation and curve fitting using a number of different equations. The shape of the response curve suggested the use of a sigmoidal function, and the best results, as measured by fit residual to omitted data points, were achieved using overlapping, piecewise fitting with Hill's equation to the lower and upper portions of the curve. The formulation of Hill's equation used is

$y(x)=y_{0}+\left(y_{\max }-y_{0}\right)\left[1+\left(\frac{x_{\text {half }}}{x}\right)^{p}\right]^{-1}$,

where the fit parameters are $y_{0}$, the base value of the function; $y_{\max }$, the maximum value; $x_{\text {half }}$, the $x$ value corresponding to the mid-point between $y_{0}$ and $y_{\max }$; and $p$, a rate coefficient. With these fits, the maximum residual error observed was less than $3 \%$ in all cases, and typically less than $2 \%$. Values in the overlap region between the upper and lower curve fits were calculated by a weighted average of the two fits in order to produce a smooth transition. The differences between the fits were typically $<1 \%$. An example of the instrument $\mathrm{H}_{3} \mathrm{O}^{+}$signal as a function of the $\mathrm{H}_{2} \mathrm{O}$ mixing ratio is shown in Fig. 6 for a laboratory calibration. The merged Hill equation fit and uncertainty in the curve fit appear in the plot as the dashed line and grey shaded region. Figure 7 shows the derived sensitivity $\left(\mathrm{H}_{3} \mathrm{O}^{+} / \mathrm{H}_{2} \mathrm{O}\right.$ in $\left.\mathrm{Hz} \mathrm{ppm}^{-1}\right)$ of the instrument as a function of the $\mathrm{H}_{2} \mathrm{O}$ mixing ratio.

\subsubsection{Background artifact}

Conceptually, the CIMS $\mathrm{H}_{2} \mathrm{O}$ background artifact is the apparent $\mathrm{H}_{2} \mathrm{O}$ mixing ratio that would be calculated from the instrument signal if there were no $\mathrm{H}_{2} \mathrm{O}$ present in the sample flow entering the instrument. Such an artifact could potentially arise from leaks into the system, outgassing of $\mathrm{H}_{2} \mathrm{O}$ from inlet surfaces, or spurious production of $\mathrm{H}_{3} \mathrm{O}^{+}$in the ion source (e.g., from $\mathrm{CH}_{4}$ ). To determine this background artifact, a completely desiccated sample air could be introduced into the inlet and the resulting signal observed. This approach would be most useful for determining the artifact arising from a leak or a chemical source, since the associated 


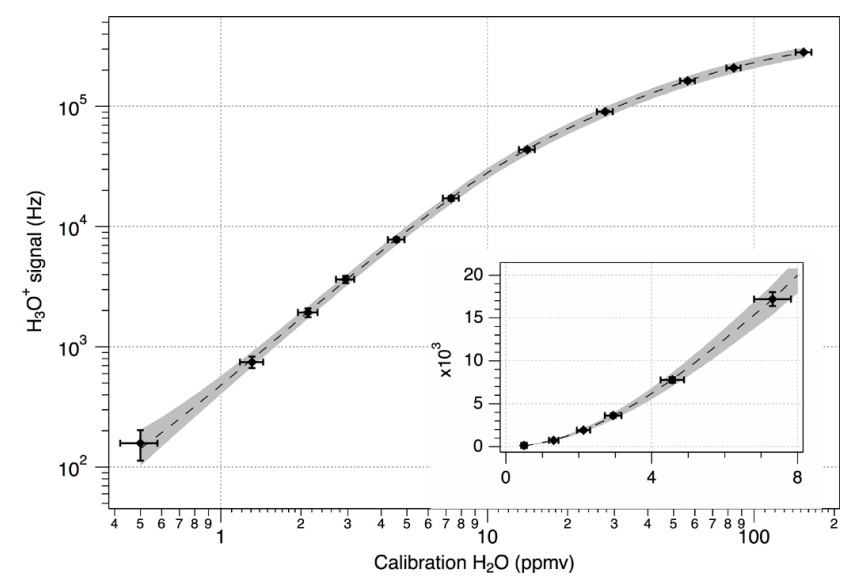

Fig. 6. CIMS calibration curve showing the non-linearity of the response to $\mathrm{H}_{2} \mathrm{O}$. The data are fit piecewise using two overlapping Hill equation (sigmoidal) curves, one for the lower 7 data points and one for the upper 7 data points. The grey shaded region represents the experimental uncertainty in the fit.

$\mathrm{H}_{3} \mathrm{O}^{+}$signals are not expected to change over time following the addition of desiccated air and should be representative of the artifact contribution to the overall signal while sampling ambient air. However, due to the equilibrium nature of surface-adsorbed $\mathrm{H}_{2} \mathrm{O}$ and the long effective time constant for the outgassing of adsorbed $\mathrm{H}_{2} \mathrm{O}$ at low concentrations ( $\mathrm{Li}$ and Dylla, 1994; Dobrozemsky et al., 2007), the $\mathrm{H}_{3} \mathrm{O}^{+}$signal arising from outgassing $\mathrm{H}_{2} \mathrm{O}$ would be a slowly decreasing value rather than constant in time. The artifact value determined for $\mathrm{H}_{2} \mathrm{O}$ outgassing into desiccated air would not be directly applicable for determining the desorption contribution to the artifact in ambient air since both the magnitude and time constant of the decaying signal would be a function of the $\mathrm{H}_{2} \mathrm{O}$ in the sample flow. Hence, adding desiccated air is not necessarily an effectual approach for determining the contribution to the instrument signal from desorbing $\mathrm{H}_{2} \mathrm{O}$ at ambient $\mathrm{H}_{2} \mathrm{O}$ values. For our CIMS inlet system, we argue that a better and more effective approach is to conduct a multipoint calibration with at least one calibration point at a mixing ratio lower than the lowest expected ambient value. In this way, any background artifact contributes to the $\mathrm{H}_{3} \mathrm{O}^{+}$signal during the calibration process in the same manner as it does when sampling ambient air. Thus, a background artifact is automatically accounted for in the CIMS $\mathrm{H}_{2} \mathrm{O}$ sensitivity calculation without explicit knowledge of the artifact value. For the CIMS $\mathrm{H}_{2} \mathrm{O}$ measurement, the lowest calibration mixing ratio was that of the zero air, with different cylinders having measured values between 0.5 and $0.8 \mathrm{ppm}$. At these mixing ratios, a stable $\mathrm{H}_{3} \mathrm{O}^{+}$signal was achieved in a reasonable time $(<60 \mathrm{~s})$, even starting from mixing ratios of several hundred ppm.

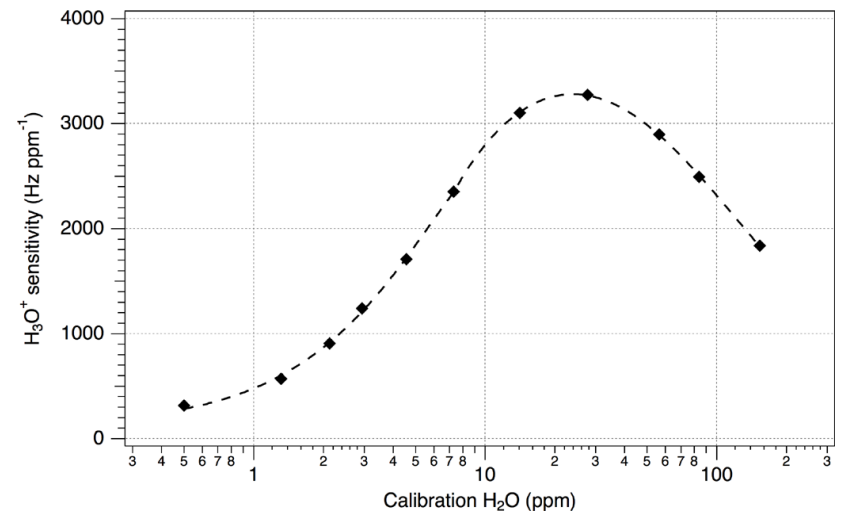

Fig. 7. The sensitivity of the CIMS measurement as a function of the $\mathrm{H}_{2} \mathrm{O}$ mixing ratio from the calibration shown in Fig. 6. The diamonds are the values from the individual calibration points, and the dashed line is the curve fit.

\subsubsection{Accuracy}

The primary standard used to evaluate the accuracy of the CIMS $\mathrm{H}_{2} \mathrm{O}$ measurement was a NIST (National Institute of Standards and Technology)-traceable, reference chilled mirror hygrometer (model 373LX, MBW Calibration Ltd., Switzerland). The MBW model 373LX (MBW hereafter) has a lower limit frost point temperature of $-95^{\circ} \mathrm{C}$ and a stated accuracy of $\pm 0.1^{\circ} \mathrm{C}$. At $1013 \mathrm{hPa}$ pressure this translates to a minimum detectable mixing ratio of less than $0.04 \mathrm{ppm}$ and an uncertainty of $\pm 0.08 \mathrm{ppm}(<2 \%)$ at $5 \mathrm{ppm}$. While the MBW has both high accuracy and precision, it operates best as a steady-state instrument and has a slow time response at low water vapor concentrations that limits its direct use for dynamic measurements such as from aircraft in the UT/LS.

The MBW was used to determine the $\mathrm{H}_{2} \mathrm{O}$ mixing ratio in zero air cylinders and to show routinely in the laboratory that the two calibration sources used in flight, namely, Ptcatalyzed $\mathrm{H}_{2}$ oxidation and the single-point $\mathrm{H}_{2} \mathrm{O}$ standard, were accurate to within a few percent. In practice, the ultimate accuracy of the $\mathrm{CIMS}_{2} \mathrm{O}$ measurement was evaluated in the laboratory by simultaneous measurement of a range of $\mathrm{H}_{2} \mathrm{O}$ mixing ratios with the MBW and CIMS sampling from a common manifold. During these intercomparisons, the CIMS instrument was operated and calibrated using the same calibration and data reduction procedures as used in flight. The CIMS measurement exhibited agreement better than $3 \%$ over a wide mixing ratio range, as is shown in an example in Fig. 8.

\subsubsection{Precision}

The precision of the CIMS measurement was evaluated by comparing the observed standard deviation in the $\mathrm{H}_{3} \mathrm{O}^{+}$signal while sampling a flow with constant $\mathrm{H}_{2} \mathrm{O}$ mixing ratio to the value expected from Poisson statistics for pulse-counting noise in the mass spectrometer electron 
multiplier. The observed ratio was 1.2, indicating that there were no significant additional sources of instrument noise. The observed instrument precision $(2 \sigma, 1 \mathrm{~s})$ at $3 \mathrm{ppm}$ was $<0.07 \mathrm{ppm}$, or $\sim 2 \%$. Precision contributed only slightly to the overall measurement uncertainty.

\subsubsection{Uncertainty}

The uncertainty of the CIMS measurement of $\mathrm{H}_{2} \mathrm{O}$ mixing ratio is tied directly to the accuracy of the $\mathrm{H}_{2} \mathrm{O}$ amounts delivered to the instrument during a calibration. The factors that contribute to the overall measurement uncertainty include the uncertainty in the measured calibration and sample flows, the uncertainty in the mixing ratios of $\mathrm{H}_{2}$ and $\mathrm{H}_{2} \mathrm{O}$ in the calibration flow and zero air, the uncertainty in the efficiency of the Pt catalyst in converting $\mathrm{H}_{2}$ to $\mathrm{H}_{2} \mathrm{O}$, the error in the curve fit representation of the calibration data, and the uncertainty arising from interpolating the sensitivity between calibrations.

\subsection{Operation on the NASA WB-57F during MACPEX}

During the Mid-latitude Airborne Cirrus Properties Experiment (MACPEX) campaign, the CIMS instrument was flown in the fourth (aft-most) pallet position on the WB-57F. The instrument operated fully autonomously following instrument power-on from the cockpit. The instrument pumps were turned on to begin instrument flow and pump-down of the vacuum chamber when the aircraft passed a pressure level of $600 \mathrm{hPa}$ (approximately $4 \mathrm{~km}$ ) during initial ascent. Data acquisition began as soon as the vacuum chamber reached operating pressure for the electron multiplier $\left(<10^{-5} \mathrm{hPa}\right)$. The instrument operated throughout the flight following a programmed measurement and calibration sequence and shut down when the aircraft descended past $600 \mathrm{hPa}$. The quadrupole mass filter was set to transmit $\mathrm{H}_{3} \mathrm{O}^{+}$ions for $9 \mathrm{~s}$, followed by $\mathrm{NO}^{+}$and $\mathrm{O}_{2}^{+}$for $0.5 \mathrm{~s}$ each. Data were acquired at a rate of $10 \mathrm{~Hz}$ and reported as $1 \mathrm{~s}$ averages.

\subsubsection{In-flight calibration}

During MACPEX flights, the CIMS $\mathrm{H}_{2} \mathrm{O}$ instrument was calibrated at mixing ratios ranging from $0.5-0.8 \mathrm{ppm}$ (depending on the $\mathrm{H}_{2} \mathrm{O}$ content of the individual flight zero air cylinder) to $153 \mathrm{ppm}$ using the Pt-catalyzed $\mathrm{H}_{2}$ oxidation system. Calibrations were automatically performed every $42-46 \mathrm{~min}$ during a $4.5-6 \mathrm{~h}$ flight. Additional single-point calibrations using the $\mathrm{H}_{2} \mathrm{O}$ in zero air standard were conducted during every other calibration sequence. Figure 9 shows a typical in-flight calibration sequence including a calibration from the single-point $\mathrm{H}_{2} \mathrm{O}$ standard. During a calibration sequence, a $2500 \mathrm{sccm}$ flow of zero air was added to the inlet, providing $\sim 1000 \mathrm{sccm}$ overflow from the inlet opening to ensure no ambient air was sampled. After $30 \mathrm{~s}$, a mass scan from $\mathrm{m} / z 16$ to $\mathrm{m} / \mathrm{z} 43.5$ was recorded to allow an assessment of the stability of peak shape and position in the mass spectrum.

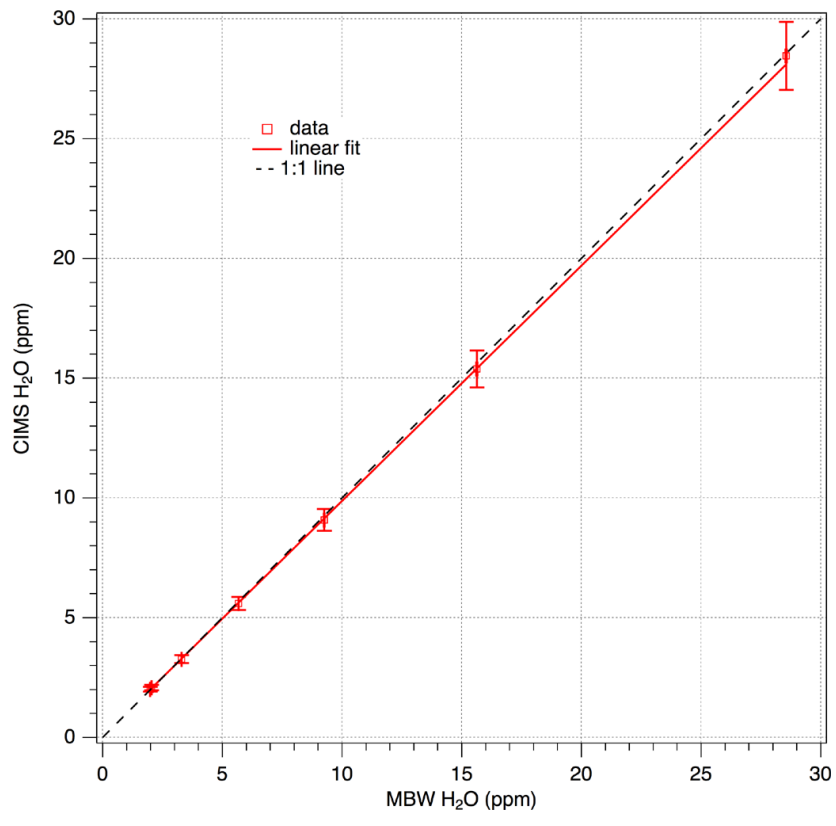

Fig. 8. Comparison of CIMS-measured $\mathrm{H}_{2} \mathrm{O}$ mixing ratios to MBW-measured mixing ratios in a laboratory experiment. The black dashed line is the $1: 1$ line, and the weighted, orthogonal linear regression fit to the data (red line) is CIMS $=0.06( \pm 0.05)+0.98$ $( \pm 0.01) \cdot$ MBW.

After $90 \mathrm{~s}$, the flow of zero air was replaced with a $2500 \mathrm{sccm}$ flow from the $\mathrm{H}_{2} \mathrm{O}$ cylinder for $120 \mathrm{~s}$ in order to ensure a stable signal. Following the $\mathrm{H}_{2} \mathrm{O}$ standard measurement, the zero air flow to the inlet was resumed. 60 s later, the calibration flow diversion valve (V3 in Fig. 1) was closed so that flow from the $\mathrm{H}_{2}$ oxidation system was added to the zero air in the sample flow. The $\mathrm{H}_{2}$ calibration standard flows were adjusted in a series of 11 steps in order to generate increasing mixing ratios from 0.8 (zero air only) to $\sim 153 \mathrm{ppm}$. In each step, the new mixing ratio was stable after $20 \mathrm{~s}$ and then averaged for $10 \mathrm{~s}$ for a total of $30 \mathrm{~s}$ per step. Following the final calibration step, the calibration diversion valve was opened and after $10 \mathrm{~s}$ the zero air flow was stopped, returning the instrument to ambient sampling. The entire calibration sequence required $640 \mathrm{~s}$ to complete; the calibration sequence without the single-point $\mathrm{H}_{2} \mathrm{O}$ standard required $495 \mathrm{~s}$. The resulting calibration curve from the calibration shown in Fig. 9, including the single-point gravimetric standard, appears in Fig. 10. The calibration curves determined by the in-flight calibrations were indistinguishable from those measured in calibrations on the ground (e.g., Fig. 6).

Ambient $\mathrm{H}_{2} \mathrm{O}$ mixing ratios were calculated using a linear interpolation of the measured sensitivity curves between adjacent calibrations. The contribution of this interpolation to the uncertainty in the calculated mixing ratio at a given point in time was estimated from the difference between the mixing ratios calculated at that point using the preceding and subsequent calibrations, weighted by the inverse of the time interval from each calibration. This results in a maximum 
contribution to the uncertainty from the interpolation at the midpoint between calibrations.

In order to verify that there were no unexpected differences between the sensitivity measured using zero air and the sensitivity in ambient air, a standard addition test was conducted following every calibration sequence by adding the $\mathrm{H}_{2} / \mathrm{Pt}-\mathrm{H}_{2} \mathrm{O}$ calibration flow directly to the ambient air sample to produce $\mathrm{H}_{2} \mathrm{O}$ mixing ratio increases of $1.2 \mathrm{ppm}$ and $3.6 \mathrm{ppm}$. When the variance in ambient mixing ratios was sufficiently low for the added $\mathrm{H}_{2} \mathrm{O}$ amounts to be reliably measured, the observed mixing ratio increase agreed with the expected value to within $5 \%$, indicating no systematic bias in the sensitivity due to calibrating in zero air.

The mixing ratios of $\mathrm{H}_{2} \mathrm{O}$ in the zero air and single-point $\mathrm{H}_{2} \mathrm{O}$ cylinders were measured before and after each flight using the MBW. The pre- and post-flight values in all cases were consistent within $\pm 0.1 \mathrm{ppm}$.

\subsubsection{Instrumental artifact}

Since the $\mathrm{H}_{2} \mathrm{O}$ concentrations at the surface are so much greater than in the UT/LS, an artifact $\mathrm{H}_{3} \mathrm{O}^{+}$signal caused by residual and/or outgassing $\mathrm{H}_{2} \mathrm{O}$ in the instrument during flight is always a concern, especially for extractive analytical techniques such as CIMS. As a consequence, effort was expended to minimize exposure of the internal surfaces of the instrument to ambient air when the instrument was not in flight. Overnight prior to a flight, the main inlet line was purged (see Fig. 1) with a small $(\sim 25 \mathrm{sccm})$ flow of zero air from an external cylinder in order to reduce exposure of the instrument flow system to ambient $\mathrm{H}_{2} \mathrm{O}$. This purge flow was maintained using the on-board zero air cylinder during installation and pre-flight, until the instrument received power on the aircraft, at which point the $2.5 \mathrm{slpm}$ zero air flow to the inlet began and continued through the instrument startup sequence. These efforts were only partially successful in preventing infiltration of ambient $\mathrm{H}_{2} \mathrm{O}$ into the instrument calibration and zero air flow paths. $\mathrm{H}_{2} \mathrm{O}$ contamination in the zero air and calibration lines caused the actual $\mathrm{H}_{2} \mathrm{O}$ amount delivered to the inlet line during the first and second calibrations to be higher than the calculated value, resulting in an overestimate of the sensitivity and leading to a negative bias in the calculated $\mathrm{H}_{2} \mathrm{O}$ mixing ratio. As a result, $\mathrm{H}_{2} \mathrm{O}$ mixing ratios could not be accurately calculated for the first $\sim 45 \mathrm{~min}$ of a flight due to uncertainty in the absolute value of the calibration mixing ratios. The magnitude of this potential bias during subsequent portions of a flight was assessed by comparing the mixing ratios observed in flight for the $\mathrm{H}_{2} \mathrm{O}$ standard to the values determined pre- and post-flight with the MBW. The excellent agreement (better than 5\%) found between the in-flight value measured by the CIMS and the MBW determination indicated that there was not a significant bias in the CIMS measurement from $\mathrm{H}_{2} \mathrm{O}$ contamination in the zero air and calibration lines after the first hour of flight.
Table 1. Summary of typical $\mathrm{H}_{2} \mathrm{O}$ CIMS performance metrics during the MACPEX campaign.

\begin{tabular}{ll}
\hline Sensitivity $^{\mathrm{a}}$ & $\sim 2000 \mathrm{~Hz} \mathrm{ppm}^{-1}$ (at $\left.3 \mathrm{ppm}\right)$ \\
Signal to noise $^{\mathrm{a}}$ & $32(1 \mathrm{~s}, 2 \sigma$, at $3 \mathrm{ppm})$ \\
Quantification limit & $0.5-0.8 \mathrm{ppm}^{\mathrm{b}}$ \\
Data rate & $10 \mathrm{~Hz}$, averaged to $1 \mathrm{~s}$ \\
Total uncertainty & $9-11 \%$ \\
Response time & $\mathrm{c}$ \\
Calibrated range & $<3 \mathrm{~s}$ \\
Weight & $0.5-153 \mathrm{ppm}$ \\
Power & $220 \mathrm{~kg}$ \\
\hline
\end{tabular}

a Average over seven UT/LS flights in the MACPEX campaign. For the last two flights, re-optimization of the ion transmission optics in the mass spectrometer resulted in a factor of 1.9 increase in sensitivity and 1.4 increase in signal to noise over the values observed during the first five flights. ${ }^{b}$ Quantification limit (lower limit of quantification) is set by the value of the lowest calibration point (zero air). ${ }^{\mathrm{c}}$ Time required to reach $95 \%$ ( $3 e$-folding times) of the decay to the final value following a step change down in mixing ratio at low-ppm mixing ratios.

\subsubsection{In-flight performance}

The CIMS $\mathrm{H}_{2} \mathrm{O}$ instrument operated successfully on seven science flights during the MACPEX campaign. A summary of the typical performance metrics for the instrument is shown in Table 1 . The overall duty cycle of the measurement, accounting for calibrations, was 0.68 . Propagation of uncertainties from all factors contributing to the calculation of $\mathrm{H}_{2} \mathrm{O}$ mixing ratios (see Table 2) in flight yields a total measurement uncertainty ranging from 9 to $11 \%$. Statistically determined uncertainties were estimated at the $2 \sigma$ level, and where the individual uncertainties are independent, the uncertainties were combined in quadrature.

One issue with sampling $\mathrm{H}_{2} \mathrm{O}$ through an inlet line is the potential effect on the measurement response time of $\mathrm{H}_{2} \mathrm{O}$ equilibration with inlet surfaces. The in situ calibrations of the CIMS instrument provide an opportunity to directly assess the inlet response time. The observed $\mathrm{H}_{3} \mathrm{O}^{+}$signals exhibit exponential decay behavior following sharp transitions in $\mathrm{H}_{2} \mathrm{O}$ in the instrument inlet from addition of zero air or diversion of calibration gas away from the inlet. Analysis of these transitions reveals that the time required to reach $95 \%$ of the decay to the final value ( $3 e$-folding times) is less than $3 \mathrm{~s}$ following an approximate step change of several ppm in $\mathrm{H}_{2} \mathrm{O}$ at mixing ratios of a few ppm. The response time becomes significantly shorter with increasing mixing ratio, and equilibration to step increases in $\mathrm{H}_{2} \mathrm{O}$ is generally faster than to similar decreases. The similarity in the inlet time constants observed for addition of zero air $3 \mathrm{~cm}$ from the sample point and calibration gas added $15 \mathrm{~cm}$ from the sample point lends confidence that no significant hysteresis is induced by the smooth inlet tubing, as expected from the materials tests described above.

The time series of $\mathrm{H}_{2} \mathrm{O}$ mixing ratios measured by CIMS during the MACPEX science flight on 25 April 2011 is shown in Fig. 11 along with the ambient pressure (inverted 


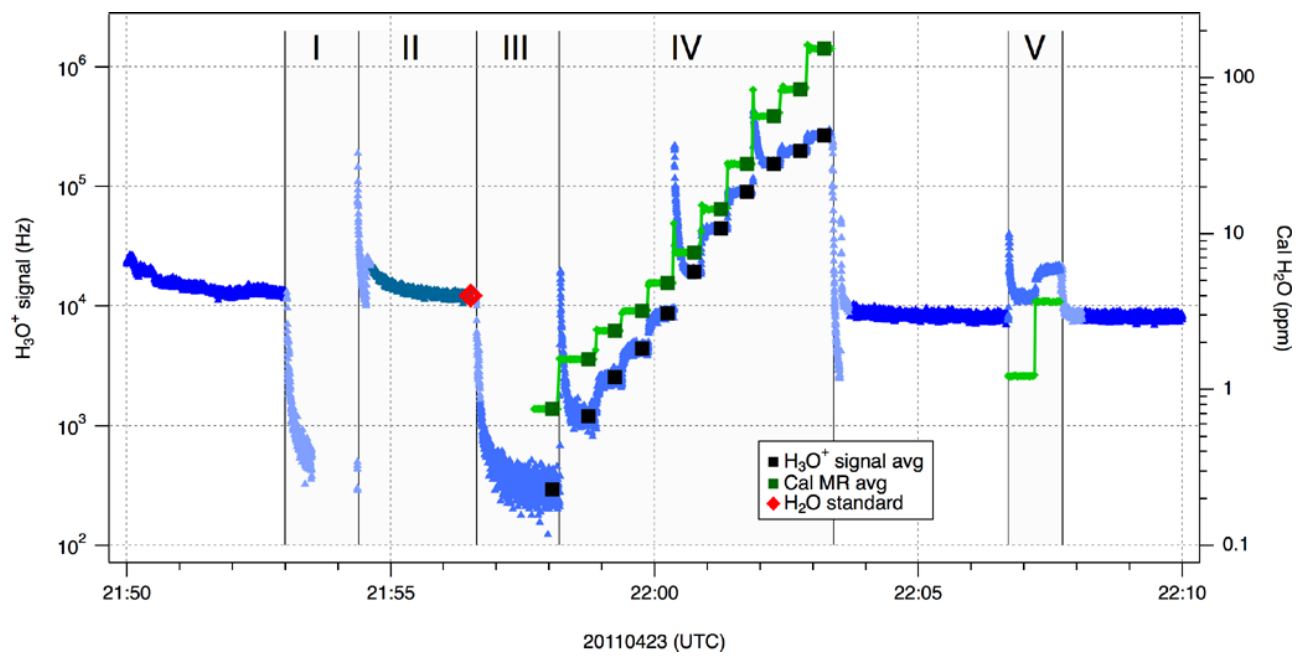

Fig. 9. In-flight calibration sequence from the flight on 23 April 2011. The small blue symbols are the $\mathrm{H}_{3} \mathrm{O}^{+}$signal and the green trace is the $\mathrm{H}_{2}$-generated $\mathrm{H}_{2} \mathrm{O}$ calibration mixing ratio. The enumerated shaded regions in the plot denote zero air and calibration gas flow to the inlet. Regions I and III are zero air alone, region II is the $\mathrm{H}_{2} \mathrm{O}$ standard, region IV is zero air plus $\mathrm{H}_{2} / \mathrm{Pt}_{-} \mathrm{H}_{2} \mathrm{O}$ calibration flow, and region V is the $\mathrm{H}_{2} / \mathrm{Pt}-\mathrm{H}_{2} \mathrm{O}$ standard addition to ambient air. The spikes that appear in three of the calibration steps in region IV are caused by a burst in the $\mathrm{H}_{2}$ flow when the 3-way solenoid valves switch the calibration flows from the higher pressure in the dump line to the catalyst. The signal from the bursts decays rapidly $(\tau<2 \mathrm{~s})$ and does not affect the average value calculated during the last $10 \mathrm{~s}$ of the calibration step. The red diamond denotes the average $\mathrm{H}_{3} \mathrm{O}^{+}$signal during the last $10 \mathrm{~s}$ of the $\mathrm{H}_{2} \mathrm{O}$ standard, the black squares are the average $\mathrm{H}_{3} \mathrm{O}^{+}$signal during the last $10 \mathrm{~s}$ of each $\mathrm{H}_{2} / \mathrm{Pt}-\mathrm{H}_{2} \mathrm{O}$ calibration step, and the green squares are the calculated absolute $\mathrm{H}_{2} \mathrm{O}$ mixing ratios for the last $10 \mathrm{~s}$ of each calibration step. The mass scan performed during the calibration resulted in the apparent data gap in region I.
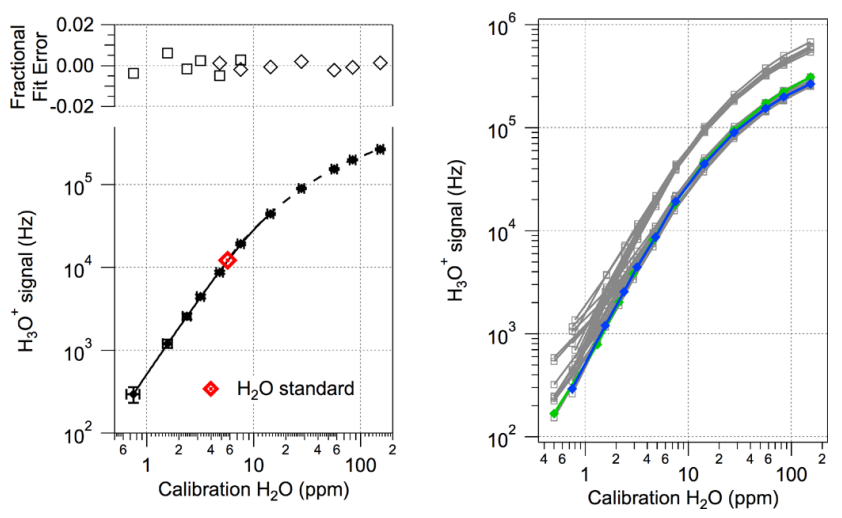

Fig. 10. The plot on the left shows the $\mathrm{H}_{3} \mathrm{O}^{+}$signals from the calibration sequence shown in Fig. 9. The solid squares are $10 \mathrm{~s}$ average values of the signal plotted against the $\mathrm{H}_{2} \mathrm{O}$ mixing ratio calculated for the calibration steps. The open squares are the fractional residual from the lower Hill equation fit (solid line) and the open diamonds are the fractional residuals from the upper Hill equation fit (dashed line). The red diamond is the calibration point from the gravimetric $\mathrm{H}_{2} \mathrm{O}$ standard, demonstrating the excellent agreement between the gravimetric and $\mathrm{H}_{2}$ calibrations. The plot on the right shows the calibration curves from all MACPEX flights. The blue curve is the calibration shown in Fig. 9, and the green curve is the laboratory calibration shown in Fig. 6. The upper set of calibration curves are from the flights on 25 and 26 April, after the ion optics voltages were re-optimized to increase the signal. scale). On this flight, the mixing ratios during the in-cloud measurement legs in the middle of the flight were below the upper end of the CIMS calibration range $(\sim 150 \mathrm{ppm})$ and therefore could be quantified. During the final high-altitude leg on the return to Ellington field, $\mathrm{H}_{2} \mathrm{O}$ reached its minimum value near $4.3 \mathrm{ppm}$ just prior to final descent. Two features observed during this flight highlight the capabilities of the CIMS $\mathrm{H}_{2} \mathrm{O}$ measurement and are shown in greater detail in Figs. 12 and 13. First, the averaged $1 \mathrm{~s}$ data and the raw $10 \mathrm{~Hz}$ data during a short in-cloud segment of this flight are shown in Fig. 12. Significant structure in $\mathrm{H}_{2} \mathrm{O}$ on small scales is clearly visible in the $10 \mathrm{~Hz}$ data (which corresponds to $\sim 20 \mathrm{~m}$ spatial scale at aircraft speeds) that is not fully represented in the $1 \mathrm{~s}$ average values. This additional structure demonstrates the fast response time of the instrument to ambient $\mathrm{H}_{2} \mathrm{O}$ fluctuations at timescales of less than $1 \mathrm{~s}$. The inlet response time determined from step changes in zero air and calibration flows, discussed above, is a conservative estimate of the actual response time to ambient fluctuations since rapid variations do not have time to saturate or deplete the $\mathrm{H}_{2} \mathrm{O}$ adsorbed to inlet surfaces ( $\mathrm{Li}$ and Dylla, 1994). Second, measured $\mathrm{H}_{2} \mathrm{O}$ mixing ratios from the final high-altitude segment of the flight are plotted in Fig. 13 along with $\mathrm{O}_{3}$ mixing ratios measured by the $\mathrm{NOAA} \mathrm{O}_{3}$ instrument (Gao et al., 2012). Over the period shown, the aircraft ascended from 13.9 to $16.9 \mathrm{~km}$ and descended back to $13.9 \mathrm{~km}$. The high precision of the $\mathrm{CIMS}_{2} \mathrm{O}$ measurement $(<0.1 \mathrm{ppm})$ allows the correlation in the structure between the $\mathrm{H}_{2} \mathrm{O}$ and $\mathrm{O}_{3}$ mixing ratios to be clearly observed. 


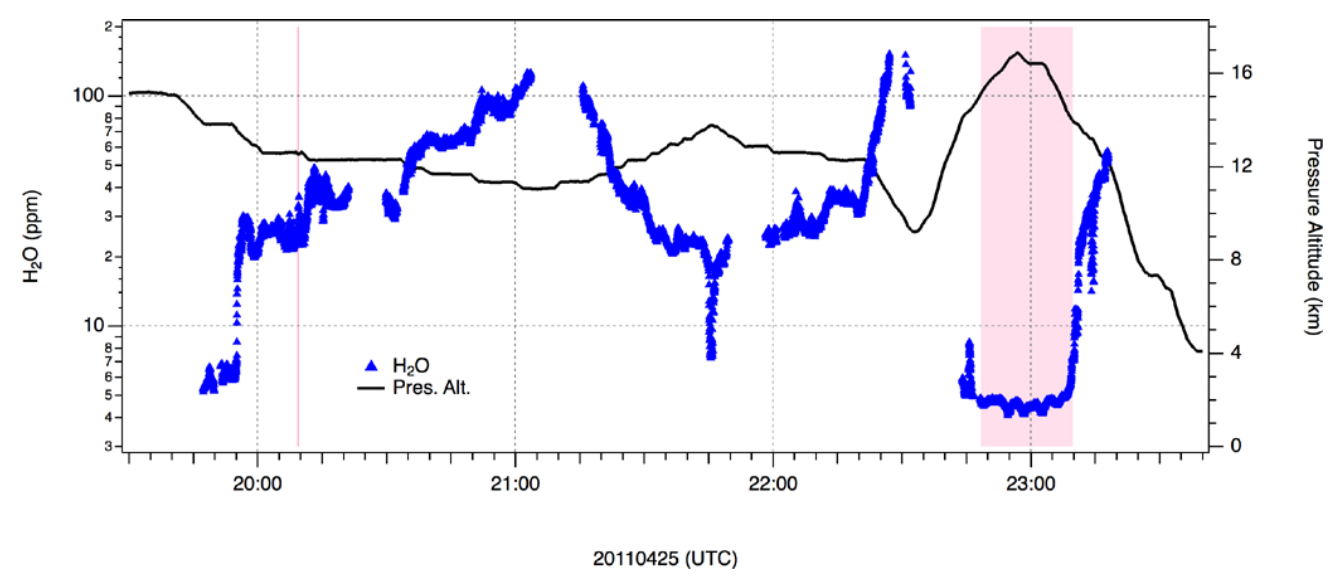

Fig. 11. Time series of $\mathrm{H}_{2} \mathrm{O}$ mixing ratios (blue) measured by the CIMS instrument and aircraft pressure altitude (black) from the MACPEX science flight on 25 April 2011. The highlighted sections correspond to the segments shown in greater detail in Figs. 12 and 13.

Table 2. Summary of components of uncertainty for the $\mathrm{H}_{2} \mathrm{O}$ CIMS measurement during the MACPEX campaign.

\begin{tabular}{ll}
\hline Source of uncertainty & Uncertainty \\
\hline $\mathrm{H}_{2}$ standards & $< \pm 2 \%$ \\
Zero air $\mathrm{H}_{2} \mathrm{O}$ content & $< \pm 0.1 \mathrm{ppm}$ \\
Flow controller accuracy & $< \pm 3 \%$ \\
$\mathrm{H}_{2}$ catalytic conversion efficiency & $<-1 \%$ \\
Calibration curve fitting & $< \pm 2 \%$ \\
Zero artifact & $<+0.1 \mathrm{ppm}$ \\
Interferences & $< \pm 0.5 \%$ \\
Interpolation between calibrations & $< \pm 4 \%$ \\
\hline Overall measurement uncertainty* & $9-11 \%$ \\
\hline * At mixing ratios $>3$ ppm observed during MACPEX
\end{tabular}

\section{Discussion}

A number of attempts have been made during the last decade to determine the source(s) of the significant discrepancies observed among in situ UT/LS $\mathrm{H}_{2} \mathrm{O}$ measurements. Groundbased comparisons and comparisons of laboratory calibration standards have generally yielded better agreement than is observed in flight. These results indicate that there are unrecognized errors that arise in the measurements by some or all of these instruments under the sampling conditions they experience in the UT/LS. A complication in determining the sources of these errors is the lack of representative, in situ, calibration and background determinations by any of the instruments under in-flight UT/LS sampling conditions.

The success of the MACPEX deployment of the CIMS $\mathrm{H}_{2} \mathrm{O}$ instrument demonstrates the power of applying this calibrated technique for the measurement of low $\mathrm{H}_{2} \mathrm{O}$ mixing ratios the UT/LS. The excellent agreement demonstrated here between two in situ calibration sources for $\mathrm{H}_{2} \mathrm{O}$ measurements below $10 \mathrm{ppm}$ in the UT/LS has no precedent and,

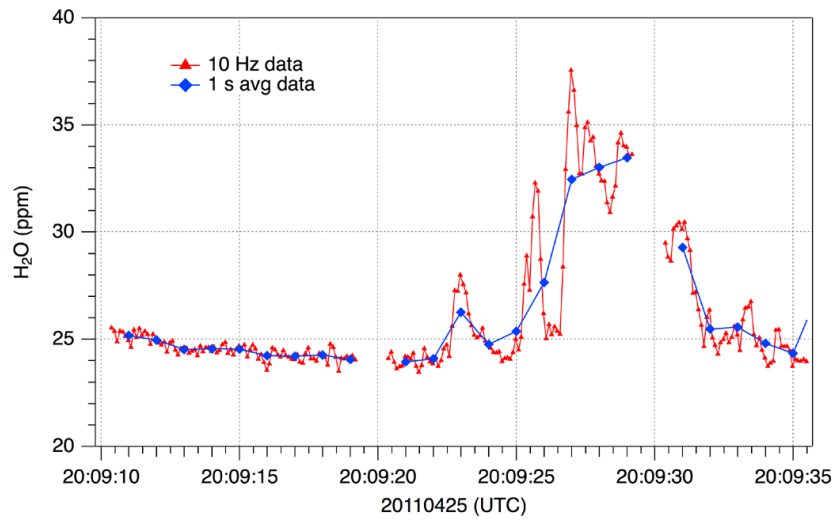

Fig. 12. Time series of CIMS $\mathrm{H}_{2} \mathrm{O} 10 \mathrm{~Hz}$ data (red triangles) and corresponding $1 \mathrm{~s}$ averages (blue diamonds) during sampling within a cirrus cloud on the flight on 25 April 2011. The $10 \mathrm{~Hz}$ data reveal additional structure in the $\mathrm{H}_{2} \mathrm{O}$ mixing ratio on smaller spatial scales $(\sim 20 \mathrm{~m})$ than those resolved with the $1 \mathrm{~s}$ data $(\sim 200 \mathrm{~m})$.

combined with the consistency of the calibrations between laboratory and flight environments, provides significant confidence in the measurements. These results show that in situ calibration flows of $\mathrm{H}_{2} \mathrm{O}$ can be accurately and routinely provided in a physically challenging aircraft environment. We note that other in situ techniques incorporating extractive sampling (e.g., Lyman- $\alpha$ photofragment fluorescence, tunable diode laser absorption, and chilled mirror) could potentially adopt the CIMS calibration system. The calibration system that has been developed and deployed with the new CIMS $\mathrm{H}_{2} \mathrm{O}$ instrument should provide a useful tool for addressing issues of measurement accuracy and consistency from flight to flight.

The CIMS $\mathrm{H}_{2} \mathrm{O}$ technique has a number of further advantages and some disadvantages. A primary advantage is the potential for higher signal to noise $(\mathrm{S} / \mathrm{N})$ than is achieved with any other existing $\mathrm{H}_{2} \mathrm{O}$ measurement technique. During 


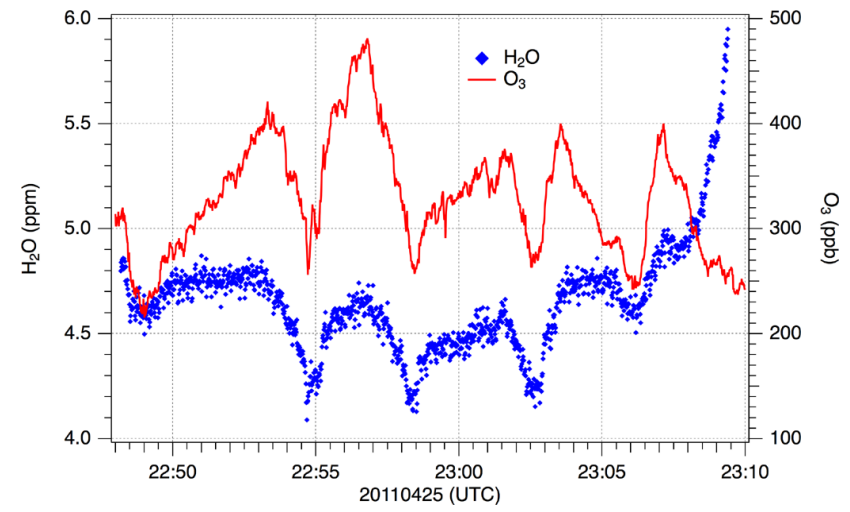

Fig. 13. Measured $\mathrm{H}_{2} \mathrm{O}$ mixing ratios (blue) on the flight on 25 April 2011 in the lower stratosphere (13.9-16.9 km) showing the excellent measurement precision at low mixing ratios. Also shown are coincident $\mathrm{O}_{3}$ mixing ratios (red) measured by the NOAA $\mathrm{O}_{3}$ instrument that display a correlated structure to that observed in $\mathrm{H}_{2} \mathrm{O}$.

the first aircraft flights the ionization source pressure was adjusted to achieve a high sensitivity and correspondingly high $\mathrm{S} / \mathrm{N}$ while maintaining a useful dynamic range for the UT/LS region (1-150 ppm). An increase in $\mathrm{S} / \mathrm{N}$ by a factor of 3 or more is easily achievable if reduced dynamic range is acceptable. Higher $\mathrm{S} / \mathrm{N}$ could be useful for investigating extremely dry regions of the atmosphere. Secondly, the ability to operate the detector under low-pressure conditions offers a significant advantage over other analytical techniques because it provides the basis for a short response time and minimizes the potential for the outgassing artifact to influence the measurements. Thirdly, because the mass spectrometer detection region is downstream and at significantly lower pressure than the ion source chamber, outgassing into this region does not produce $\mathrm{H}_{3} \mathrm{O}^{+}$ions to interfere with the measurement.

A potential disadvantage of the current CIMS instrument is its large size, weight, and power requirement, which preclude its operation on many platforms, in particular many unmanned aircraft. With current technology and optimization of the instrument design for $\mathrm{H}_{2} \mathrm{O}$ measurements, these values could be reduced substantially. A disadvantage of the CIMS technique for $\mathrm{H}_{2} \mathrm{O}$ measurements described here is the non-linearity of the sensitivity, which is a fundamental aspect of the ion-molecule chemistry arising from the direct ionization of the ambient sample. This aspect necessitates multipoint calibrations across the entire range of mixing ratios to be quantified in order to maintain uniform accuracy. Adjustments to the geometry and operating potentials of the ion source can have significant effects on the shape of the sensitivity curve and might yield simpler functional forms (e.g., power law) across the measurement range of interest. It may also be possible that the sensitivity of CIMS to $\mathrm{H}_{2} \mathrm{O}$ could be rendered linear over the range of interest with a different ion source geometry and/or different operating parameters, by doping or dynamically diluting the sample flow (e.g., with $\mathrm{O}_{2}$ or $\mathrm{N}_{2}$ ) to alter the relative importance of the different ionization pathways, or by using a typical CIMS ionization scheme in which reagent ions are generated and added to the sample flow instead of passing ambient flow through the ion source.

\section{Conclusions}

A new CIMS technique has been successfully developed for the measurement of low-ppm mixing ratios of $\mathrm{H}_{2} \mathrm{O}$. Ambient sample air flow is directly exposed to $\alpha$-particle radiation in a custom ion source and the resulting $\mathrm{H}_{3} \mathrm{O}^{+}$ions are used to quantify the $\mathrm{H}_{2} \mathrm{O}$ mixing ratio. This technique has been implemented in a CIMS instrument capable of operating in unpressurized payload spaces on a high-altitude research aircraft. Critical pressures and flows are tightly controlled to allow the instrument to operate identically in flight and on the ground. The new CIMS is unique among current UT/LS $\mathrm{H}_{2} \mathrm{O}$ instruments in that it includes a calibration system and conducts in-flight calibration with standard addition of known $\mathrm{H}_{2} \mathrm{O}$ amounts. The consistency of in-flight and laboratory calibrations demonstrates that the $\mathrm{CIMS}_{2} \mathrm{O}$ measurements in the UT/LS were not subject to significant artifacts.

The CIMS instrument flew on board the NASA WB-57F during the 2011 MACPEX campaign and measured $\mathrm{H}_{2} \mathrm{O}$ mixing ratios as low as $3.5 \mathrm{ppm}$ in the mid-latitude UT/LS. The instrument demonstrated excellent precision $(<2 \%)$ and high accuracy $(\sim 10 \%)$ across its total calibrated measurement range of $<1$ to $150 \mathrm{ppm}$. Data were acquired at $10 \mathrm{~Hz}$ and averaged to $1 \mathrm{~s}$. The high precision and fast time response allow use of the $10 \mathrm{~Hz}$ data to resolve $\mathrm{H}_{2} \mathrm{O}$ fluctuations at scales down to $20 \mathrm{~m}$ at typical aircraft speeds.

Using the new CIMS $\mathrm{H}_{2} \mathrm{O}$ instrument for UT/LS measurements is expected to contribute to resolving the issues of differences among measurements in multiple instrument intercomparisons by providing high precision measurements that are directly calibrated in flight under UT/LS conditions.

Acknowledgements. The authors thank the ground and air crews of the NASA WB-57F for their support during the MACPEX mission. This work was supported by funding from the NOAA Climate Program Office, the NASA Upper Atmosphere Research Program, the NASA Radiation Sciences Program, and the CIRES Innovative Research Program. CV was funded by HGF VH-NG-309.

Edited by: M. Sipilä 


\section{References}

Anicich, V. G.: An Index of the Literature for Bimolecular Gas Phase Cation-Molecule Reaction Kinetics, JPL Publication 0319, National Aeronautics and Space Administration/Jet Propulsion Laboratory, California Institute of Technology, 2003.

Brasseur, G. and Solomon, S.: Aeronomy of the Middle Atmosphere, 3rd Edn., Springer, Dordecht, the Netherlands, 2005.

Dobrozemsky, R., Menhart, S., and Buchtela, K.: Residence times of water molecules on stainless steel and aluminum surfaces in vacuum and atmosphere, J. Vac. Sci. Technol. A, 25, 551-556, doi:10.1116/1.2718958, 2007.

Fahey, D. W., Gao, R.-S., and Möhler, O.: Summary of the AquaVIT Water Vapor Intercomparison: Static Experiments, available at: https://aquavit.icg.kfa-juelich.de/WhitePaper/ AquaVITWhitePaper_Final_23Oct2009_6MB.pdf (last access: 22 May 2013), 2009.

Fehsenfeld, F. C., Mosesman, M., and Ferguson, E. E.: IonMolecule Reactions in an $\mathrm{O}_{2}^{+}-\mathrm{H}_{2} \mathrm{O}$ System, J. Chem. Phys., 55, 2115-2120, 1971.

Ferguson, E. E.: Laboratory Measurements of Ionospheric IonMolecule Reaction Rates, Rev. Geophys. Space Ge., 12, 703713, 1974.

Forster, P. M. de F. and Shine, K. P.: Assessing the climate impact of trends in stratosperhic water vapor, Geophys. Res. Lett., 29, 10.1-10.4, doi:10.1029/2001GL013909, 2002.

Gao, R.-S., McLaughlin, R. J., Schein, M. E., Neuman, J. A., Ciciora, S. J., Holecek, J. C., and Fahey, D. W.: Computercontrolled Teflon flow control valve, Rev. Sci. Instrum., 70, 4732-4733, 1999.

Gao, R. S., Ballard, J., Watts, L. A., Thornberry, T. D., Ciciora, S. J., McLaughlin, R. J., and Fahey, D. W.: A compact, fast UV photometer for measurement of ozone from research aircraft, Atmos. Meas. Tech., 5, 2201-2210, doi:10.5194/amt-5-2201-2012, 2012.

Hintsa, E. J., Weinstock, E. M., Anderson, J. G., May, R. D., and Hurst, D. F.: On the accuracy of in situ water vapor measurements in the troposphere and lower stratosphere with the Harvard Lyman- $\alpha$ hygrometer, J. Geophys. Res., 104, 8183-8189, doi:10.1029/1998JD100110, 1999.

Huey, L. G.: Measurement of Trace Atmospheric Species by Chemical Ionization Mass Spectrometry: Speciation of Reactive Nitrogen and Future Directions, Mass Spec. Rev., 26, 166-184, doi:10.1002/mas.20118, 2007.

Jensen, E. J., Smith, J. B., Pfister, L., Pittman, J. V., Weinstock, E. M., Sayres, D. S., Herman, R. L., Troy, R. F., Rosenlof, K., Thompson, T. L., Fridlind, A. M., Hudson, P. K., Cziczo, D. J., Heymsfield, A. J., Schmitt, C., and Wilson, J. C.: Ice supersaturations exceeding $100 \%$ at the cold tropical tropopause: implications for cirrus formation and dehydration, Atmos. Chem. Phys., 5, 851-862, doi:10.5194/acp-5-851-2005, 2005.

Jensen, E. J., Pfister, L., Bui, T. V., Lawson, P., Baker, B., Mo, Q., Baumgardner, D., Weinstock, E. M., Smith, J. B., Moyer, E. J., Hanisco, T. F., Sayres, D. S., Clair, J. M. St., Alexander, M. J., Toon, O. B., and Smith, J. A.: Formation of large $(\simeq 100 \mu \mathrm{m})$ ice crystals near the tropical tropopause, Atmos. Chem. Phys., 8, 1621-1633, doi:10.5194/acp-8-1621-2008, 2008.

Kiemle, C., Wirth, M., Fix, A., Ehret, G., Schumann, U., Gardiner, T., Schiller, C., Sitnikov, N., and Stiller, G.: First airborne water vapor lidar measurements in the tropical upper troposphere and mid-latitudes lower stratosphere: accuracy evaluation and intercomparisons with other instruments, Atmos. Chem. Phys., 8, 5245-5261, doi:10.5194/acp-8-5245-2008, 2008.

Kley, D., Russell III, J. M., and Phillips, C. (Eds.): SPARC Assessment of Upper Tropospheric and Stratospheric Water Vapour, World Clim. Res. Prog., Geneva, Switzerland, 2000.

Krämer, M., Schiller, C., Afchine, A., Bauer, R., Gensch, I., Mangold, A., Schlicht, S., Spelten, N., Sitnikov, N., Borrmann, S., de Reus, M., and Spichtinger, P.: Ice supersaturations and cirrus cloud crystal numbers, Atmos. Chem. Phys., 9, 3505-3522, doi:10.5194/acp-9-3505-2009, 2009.

Leblanc, T., McDermid, I. S., and Walsh, T. D.: Ground-based water vapor raman lidar measurements up to the upper troposphere and lower stratosphere for long-term monitoring, Atmos. Meas. Tech., 5, 17-36, doi:10.5194/amt-5-17-2012, 2012.

Li, M. and Dylla, H. F.: Model for water outgassing from metal surfaces (II), J. Vac. Sci. Technol. A, 12, 1772-1777, doi:10.1116/1.579004, 1994.

May, R. D.: Open-path, near-infrared tunable diode laser spectrometer for atmospheric measurements of $\mathrm{H}_{2} \mathrm{O}$, J. Geophys. Res., 103, 19161-19172, 1998.

Maycock, A. C., Shine, K. P., and Joshi, M. M.: The temperature response to stratospheric water vapour changes, Q. J. Roy. Meteorol. Soc., 137, 1070-1082, doi:10.1002/qj.822, 2011.

Milz, M., von Clarmann, T., Fischer, H., Glatthor, N., Grabowski, U., Höpfner, M., Kellmann, S., Kiefer, M., Linden, A., Mengistu Tsidu, G., Steck, T., Stiller, G. P., Funke, B., López-Puertas, M., and Koukouli, M. E.: Water Vapor Distributions Measured with the Michelson Interferometer for Passive Atmospheric Sounding on board Envisat (MIPAS/Envisat), J. Geophys. Res., 110, D24307, doi:10.1029/2005JD005973, 2005.

Neuman, J. A., Gao, R. S., Schein, M. E., Ciciora, S. J., Holecek, J. C., Thompson, T. L., Winkler, R. H., McLaughlin, R. J., Northway, M. J., Richard, E. C., and Fahey, D. W.: A fast-response chemical ionization mass spectrometer for in situ measurements of $\mathrm{HNO}_{3}$ in the upper troposphere and lower stratosphere, Rev. Sci. Instrum., 71, 3886-3894, doi:10.1063/1.1289679, 2000.

Peter, T., Marcolli, C., Spichtinger, P., Corti, T., Baker, M. B., and Koop, T.: When dry air is too humid, Science, 314, 1399-1402, 2006.

Popp, P. J., Gao, R. S., Marcy, T. P., Fahey, D. W., Hudson, P. K., Thompson, T. L., Kärcher, B., Ridley, B. A., Weinheimer, A. J., Knapp, D. J., Montzka, D. D., Baumgardner, D., Garrett, T. J., Weinstock, E. M., Smith, J. B., Sayres, D. S., Pittman, J. V., Dhaniyala, S., Bui, T. P., and Mahoney, M. J.: Nitric acid uptake on subtropical cirrus cloud particles, J. Geophys. Res., 109, D06302, doi:10.1029/2003JD004255, 2004.

Read, W. G., Waters, J. W., Wu, D. L., Stone, E. M., Shippony, Z., Smedley, A. C., Smallcomb, C. C., Oltmans, S., Kley, D., Smit, H. G. J., Mergenthaler, J. L., and Karki, M. K.: UARS Microwave Limb Sounder upper tropospheric humidity measurement: Method and validation, J. Geophys. Res., 106, 3220732258, 2001.

Rollins, A. W., Thornberry, T. D., Gao, R.-S., Hall, B. D., and Fahey, D. W.: Catalytic oxidation of $\mathrm{H}_{2}$ on platinum: a robust method for generating low mixing ratio $\mathrm{H}_{2} \mathrm{O}$ standards, Atmos. Meas. Tech., 4, 2059-2064, doi:10.5194/amt-4-2059-2011, 2011.

Solomon, S., Rosenlof, K. H., Portmann, R. W., Daniel, J. S., Davis, S. M., Sanford, T. J., and Plattner, G.-K.: Contributions of Strato- 
spheric Water Vapor to Decadal Changes in the Rate of Global Warming, Science, 327, 1219-1223, 2010.

Takebe, M.: Positive Ion Species and Their Mobilities in Air, Jpn. J. Appl. Phys., 13, 207-217, 1974.

Trenberth, K. E., Jones, P. D., Ambenje, P., Bojariu, R., Easterling, D., Klein Tank, A., Parker, D., Rahimzadeh, F., Renwick, J. A., Rusticucci, M., Soden, B., and Zhai, P.: Observations: Surface and Atmospheric Climate Change, in: Climate Change 2007: The Physical Science Basis. Contribution of Working Group I to the Fourth Assessment Report of the Intergovernmental Panel on Climate Change, edited by: Solomon, S., Qin, D., Manning, M., Chen, Z., Marquis, M., Averyt, K. B., Tignor, M., and Miller, H. L., Cambridge University Press, Cambridge, United Kingdom and New York, NY, USA, 2007.

Vömel, H., David, D. E., and Smith, K.: Accuracy of tropospheric and stratospheric water vapor measurements by the cryogenic frost point hygrometer: Instrumental details and observations, J. Geophys. Res., 112, D08305, doi:10.1029/2006JD007224, 2007.
Weinstock, E. M., Hintsa, E. J., Dessler, A. E., Oliver, J. F., Hazen, N. L., Demusz, J. N., Allen, N. T., Lapson, L. B., and Anderson, J. G.: New fast response photofragment fluorescence hygrometer for use on the NASA ER-2 and the Perseus remotely piloted aircraft, Rev. Sci. Instrum., 65, 3544-3554, doi:10.1063/1.1144536, 1994.

Weinstock, E. M., Smith, J. B., Sayres, D. S., Pittman, J. V., Spackman, J. R., Hintsa, E. J., Hanisco, T. F., Moyer, E. J., St. Clair, J. M., Sargent, M. R., and Anderson, J. G.: Validation of the Harvard Lyman- $\alpha$ in situ water vapor instrument: Implications for the mechanisms that control stratospheric water vapor, J. Geophys. Res., 114, D23301, doi:10.1029/2009JD012427, 2009.

Zöger, M., Afchine, A., Eicke, N., Gerhards, M. T., Klein, E., McKenna, D. S., Mörschel, U., Schmidt, U., Tuitjer, F., Woyke, T., and Schiller, C.: Fast in situ hygrometers: A new family of balloon-borne and airborne Lyman alpha photofragment fluorescence hygrometers, J. Geophys. Res.-Atmos., 104, 1807-1816, doi:10.1029/1998JD100025, 1999. 